\title{
Development of a dynamic external CFD and BES coupling framework for application of urban neighbourhoods energy modelling
}

\author{
Ruijun Zhang ${ }^{\mathrm{a}}$, Parham A. Mirzaeia ${ }^{\mathrm{k}}$, Benjamin Jones ${ }^{\mathrm{a}}$ \\ ${ }^{a}$ Department of Architecture and Built Environment, \\ The University of Nottingham, \\ Nottingham NG7 2RD, UK \\ *Corresponding author: parham.mirzaei_ahranjani@nottingham.ac.uk
}

\begin{abstract}
Current building energy models are weak at representing the interactions between neighbourhoods of buildings in cities. The effect of a neighbourhood on the local microclimate is complex, varying from one building to another and one of the most important neighbourhood effects is on the airflow around each building. A failure to account for this may lead to the miss-calculation of heat transfer and energy demand. Current building energy simulation (BES) tools apply convective heat transfer coefficient (CHTC) correlations, which were developed by using a simplified model of wind flow that neglects neighbourhood effects. Computational Fluid Dynamics (CFD) techniques are able to model these neighbourhood effects and can be used to improve CHTC correlations.

This work aims to develop a framework that couples CFD and BES tools to enhance the modelling of outdoor convective heat transfer in different urban neighbourhoods. A dynamic external coupling method was used to combine the benefits from both domains. Firstly, a microclimate CFD model was validated before the coupling stage using wind tunnel data. Secondly, the framework was tested using a benchmark model of a building block. Fully converged values of the surface temperature and $\mathrm{CHTC}$ were achieved at each time-step by the BES and CFD domains. The results highlight the importance of neighbourhood effect while the prediction of the hourly averaged external convection using coupling method can amend the simulation by up to $64 \%$ comparing to the standalone conventional BES models with DOE-2 CHTC approach.
\end{abstract}

Keywords: Coupling, CFD, building energy simulation, discharge coefficient, convective heat transfer coefficient, neighbourhood

\section{Nomenclature}

\begin{tabular}{|lcllll|}
\hline$h_{c}$ & $\mathrm{~W} / \mathrm{m}^{2} \mathrm{~K}$ & convective heat transfer coefficient & $T_{S}$ & ${ }^{\circ} \mathrm{C}$ & building surface temperature \\
$q_{c}^{\prime \prime}$ & $\mathrm{W} / \mathrm{m}^{2}$ & convective heat flux & $U$ & $\mathrm{~m} / \mathrm{s}$ & flow velocity \\
$\delta$ & $\mathrm{m}$ & site boundary layer thickness & $Z$ & $\mathrm{~m}$ & altitude, height from ground \\
$\alpha$ & & exponent of wind speed profile & $T_{a}$ & ${ }^{\circ} \mathrm{C}$ & air temperature \\
$T_{b}$ & $\mathrm{~K}$ & air temperature at ground level & $L_{a}$ & $\mathrm{~K} / \mathrm{m}$ & $\begin{array}{l}\text { air temperature gradient within } \\
\text { troposphere }\end{array}$ \\
$E_{r}$ & $\mathrm{~m}$ & radius of the Earth & $H_{b}$ & $\mathrm{~m}$ & additional height to the troposphere \\
$I$ & & turbulence intensity & $u_{z}^{\prime}$ & $\mathrm{m} / \mathrm{s}$ & rms velocity fluctuation \\
$k$ & $\mathrm{~J} / \mathrm{kg}$ & turbulence kinetic energy & $\varepsilon$ & $\mathrm{m}^{2} / \mathrm{s}^{3}$ & turbulent dissipation rate \\
\hline
\end{tabular}




\begin{tabular}{|c|c|c|c|c|c|}
\hline$C_{\mu}$ & & $k-\varepsilon$ model constant & $h^{*}$ & $\mathrm{~W} / \mathrm{m}^{2} \mathrm{~K}$ & virtual $h_{c}$ for ENERGYPLUS \\
\hline$T_{g}$ & ${ }^{\circ} \mathrm{C}$ & ground temperature & $P$ & $\mathrm{~Pa}$ & pressure \\
\hline$\rho$ & $\mathrm{kg} / \mathrm{m}^{3}$ & density & $u$ & & $\begin{array}{l}\text { fluctuating component of velocity } \\
\text { vector }\end{array}$ \\
\hline$\mu$ & & molecular viscosity & $\mu_{t}$ & $\mathrm{~kg} / \mathrm{ms}$ & eddy viscosity \\
\hline$H$ & $\mathrm{~m}$ & height of target building (prototype) & $E_{1}$ & & simulation error \\
\hline$q_{h r}$ & & hit rate & $N$ & & number of observations \\
\hline$F A C 2$ & & $\begin{array}{l}\text { fraction of predictions within a } \\
\text { factor } \\
\text { of two of observations }\end{array}$ & $i, j, k$ & & $\begin{array}{l}3 \text { dimensional component as } \\
\text { subscript }\end{array}$ \\
\hline$o$ & & observed value & $p$ & & predicted value \\
\hline$D_{q_{h r}}$ & & relative deviation of $q_{h r}$ & $W_{q_{h r}}$ & & absolute deviation of $q_{h r}$ \\
\hline$U_{c}$ & $\mathrm{~m} / \mathrm{s}$ & $\begin{array}{l}\text { computed time averaged velocity } \\
\text { vector }\end{array}$ & $U^{*}$ & $\mathrm{~m} / \mathrm{s}$ & $\begin{array}{l}\text { time averaged instantaneous scalar } \\
\text { velocity }\end{array}$ \\
\hline$L$ & $\mathrm{~m}$ & length of target building (prototype) & $w$ & $\mathrm{~m}$ & width of target building (prototype) \\
\hline
\end{tabular}

\section{Introduction}

The building sector consumes about $21 \%$ of world's delivered energy [1]. Its share is around $40 \%$ in many developed countries, such as the U.S., the U.K. and in most EU countries [2, 3]. The growth of energy demand of the built environment is expected to occur in countries with an emerging market economy [1] attributable to rapid and continuous urbanization projected up to 2030 [4]. Urbanization is accompanied by an increase in urban density, and changes to district planning and regional microclimates. With populations shifting from rural to urban locations, more attention should be placed on reducing the energy demand of buildings, especially in the urban context. In particular, a better understanding and assessment of building energy demands in cities can help decision makers to propose appropriate regulations for indoor and outdoor environments and aid urban planners in the design and modification of cities. However, they are hampered by a lack of comprehensive modelling tools capable of considering the complexity of urban morphologies and dynamic neighbourhood environments, known as the neighbourhood effect.

There are many simulation packages capable of modelling building energy demands, such as ENERGYPLUS, REVIT, DOE-2, and EQUEST. They calculate heating/cooling loads by simultaneously solving mass and energy conservation equations for a finite number of zones [5]. Convection is an important mechanism of heat transfer at a building's exterior whose effect can be two to three times larger than the radiant transfer [6-8]. Simplified outdoor airflow models have reported errors of $20-40 \%$ when predicting total building energy demand estimation [9]. Predictive errors in the calculation of convective heat transfer are related to the improper capture of local dynamic wind gradients. Current building energy simulation (BES) tools use an empirical convective heat transfer coefficient (CHTC), which is often not accurate enough for a specific case, especially in complex urban contexts where the neighbourhood effect shapes the microclimate around a building. Instead, the algorithms embedded within them treat building clusters the same way as an isolated building. This is because they were developed through specific in-situ measurements [10] and so they are unable to increase account for variations in urban morphologies. 
Computational fluid dynamics (CFD) techniques can solve the conservation laws at a small scale and are known for their strength in modelling airflows. CFD has been widely applied to environmental studies of different scales, from indoor climates to district and city communities [11-18]. However, CFD does not include the dynamic response of the buildings into the microclimate. The coupling, or integration, of CFD and BES techniques can compensate for their individual limitations and offer a more accurate assessment of the built environment. Here, CFD is used to discretise the fluid domain and BES to discretise the building energy load calculation [19].

In general, there are two methods of coupling CFD and BES tools, known as internal and external coupling. The internal approach is used to expand the capability of existing programs by developing new code. However, application of this method is very limited [20] due to its high computationally expense, convergence concerns and high cost for development [21]. Conversely, external coupling is a more widely used method, perhaps because BES and CFD techniques are each well developed, albeit separately. More accurate predictions of building energy demand can be obtained by using the advantages of each tool. Figure 1 shows different types of BES-CFD coupling. Among all the coupling methods, fully dynamic coupling provides the most accurate results as iterative calculation of each time step is guaranteed with converged results between two programs.

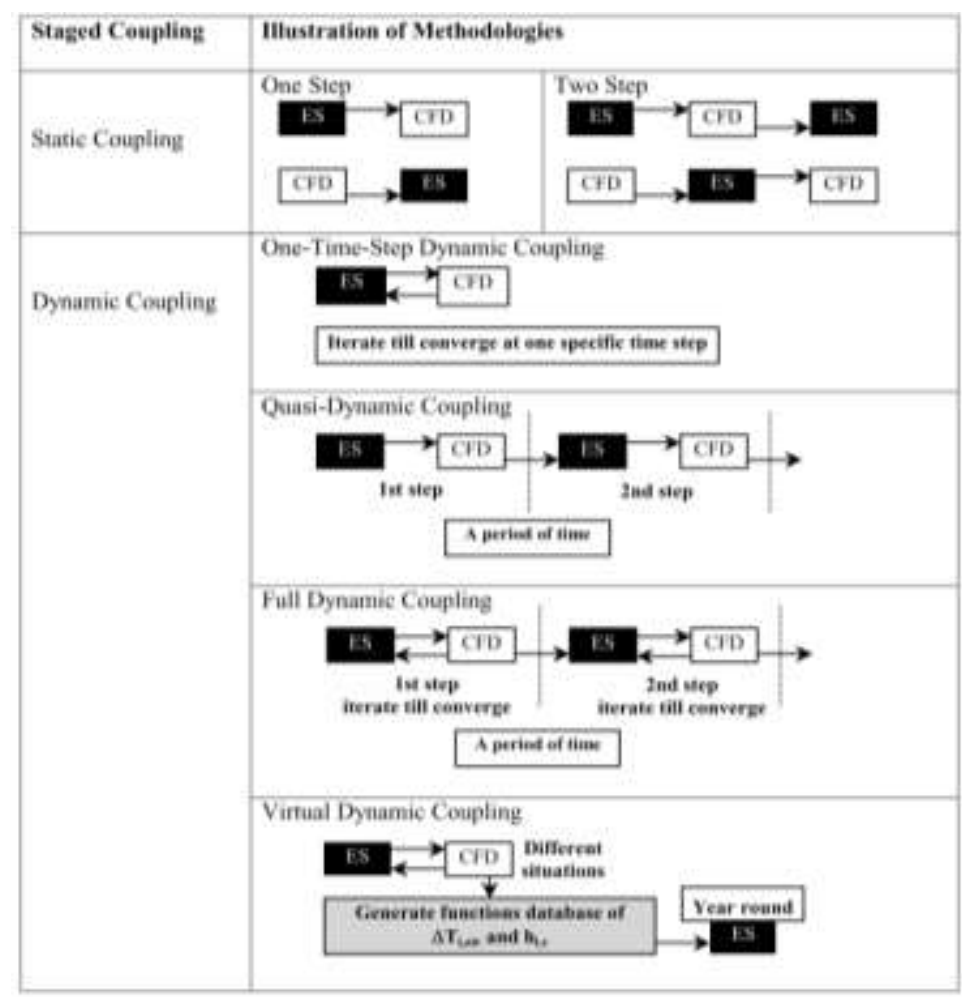

Figure 1 Different BES-CFD coupling methods [22]

Previous applications of the external coupling of CFD and BES tools have mostly focused on the prediction of CHTC for interior surfaces [5, 21, 23, 24]. Building energy demand assessment can be enhanced by using a coupling technique to take account of the effects on the microclimate of a single building of its surrounding neighbourhood. Existing studies that use outdoor coupling are very limited [25-29] ; for example, Mochida et al. [25] and Allegrini et al. [27] used the cross-ventilation rate, estimated by site-scale CFD simulation, as the input for the BES analysis. Although their CFD domain covered the outdoor environment, the main change in BES occurred inside the room due to the updated ventilation rate, but there was no significant improvement of the exterior CHTC. Nikkho et al. [29] proposed wind factors to modify the wind profiles in the BES domain. The factors were dependent 
on the local terrain and urban morphologies, but they did not differentiate between surfaces or buildings because the weather data was applied uniformly to each object in the BES domain. Yi and Feng [26] and Malys et al.[28] used CFD to improve surface CHTC for BES. Some of these studies were designed for specific cases, and so do not generally reflect miscellaneous and random urban morphologies [25, 28, 29]. Also, most of the executed couplings [25-27, 29] between tools lack an iterative process that improves predictive accuracy, and so the dynamic coupling approach is recommended.

This study aims to develop a practical and general framework for the coupling of CFD and BES tools, to improve the prediction of CHTC values, and to improve the prediction of the energy demands of buildings located in urban neighbourhoods. Section 2 outlines an appropriate coupling approach, communications between BES and CFD tools, and the CFD microclimate modelling method. Section 3 validates the CFD microclimate model using empirical measurements made in a wind tunnel so that can be used to investigate the energy demand of a case-study building. A case-study building, which is a simple city block located in Los Angeles as an example of an extreme climate, is introduced. In this section, four scenarios are explored, where the location of the case-study building is varied inside its neighbourhood to demonstrate the impact of surrounding buildings. A comparison of the external façade CHTC for each location is used to show the importance of the neighbourhood effect.

\section{Methodology}

\subsection{A general approach to couple CFD and BES tools}

The external method is adopted for the integration of BES and CFD. Mutually-consistent geometrical models are created in the BES and CFD domains with coherence in the boundary name. Buildings are tested using a fully dynamic approach to ensure that convergence is guaranteed for each time-step; see Figure 1. Here, convergence is a unique solution shared by both domains. For this study, both domains achieve the same (or with only a slight difference) convective heat flux $\left(q_{c}^{\prime \prime}\right)$ for outdoor surfaces at every time-step before moving to the next one.

A schematic of the coupling process for the building energy assessment is presented in Figure 2. The goal of this framework is to improve the assessment of the energy demand of any building or community. Information required by the framework includes site data, building designs and operation conditions. Bespoke code is used to transfer customized inputs and meteorological data between the two domains. The code passes all configurations to the BES as an input file in a standard format and generates another file with a set of commands for the CFD module to setup its boundary conditions, such as vertical wind profile. To consider the time lag phenomenon of thermal calculations, a presimulation is run for a defined period of time (from a few hours to several days) before the simulation period. The latter stage may benefit from an initial guess by the pre-simulation. Therefore, in the presimulation stage, the convective heat transfer calculations are made by the BES using its own algorithms; here those of ENERGYPLUS. Edited schedules of default CHTC values for all surfaces are then added to the BES input file. Also, the BES CHTC calculation method is amended to 'customization' or 'schedule' the empirical algorithms used to start the dynamic simulation. 

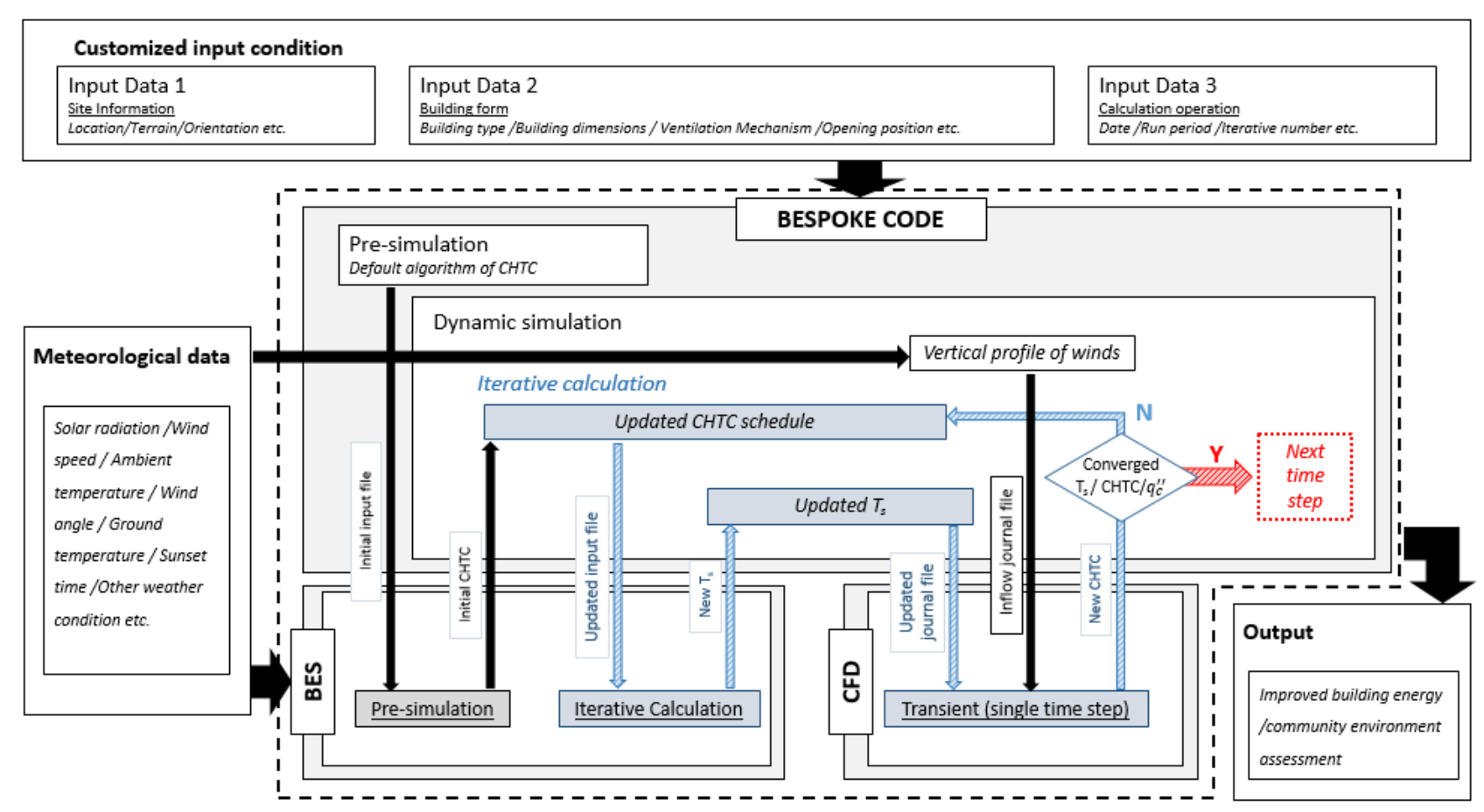

Figure 2 Framework of the coupling BES and CFD for the exterior surface convection

The core of the dynamic simulation is the iterative calculations shared between the CFD and BES domains at each time-step (shaded in blue in Figure 2). The building surface temperatures $\left(T_{s}\right)$ of the energy model, and the convective heat transfer coefficients $\left(h_{c}\right)$ of the CFD model, are the variables exchanged between the two domains. Here, $T_{s}$ is forwarded by the BES to the CFD model as a boundary condition. The CFD then returns $h_{c}$ to the BES via bespoke code. Within each time-step of the simulation period, the CHTC schedules and $T_{s}$ are updated during every iteration until convergence is achieved. It is noteworthy that the CFD domain runs a quasi-dynamic simulation, which means that the boundary conditions are fixed for the transient-flow at every time-step. An appropriate residual criterion should be assigned for the reference variable. The reference variables can separately be $T_{s}$ for BES and $h_{c}$ for CFD, or alternatively $q_{c}^{\prime \prime}$ used by either domain. If the residual meets the required criterion after two continuous iterations the loop ends and the calculation progresses to the next time-step. Otherwise, iterative calculation continues. Meteorological data are applied to the BES tool directly whereas the data are transferred into a format of journal file by the bespoke code to be read into CFD tool so that it captures the same vertical wind profile as the BES.

In this study, all energy modelling used ENERGYPLUS 8.7C, CFD simulation used ANSYS FLUENT 17.2@, and bespoke code was written in MATLAB R2017a@. ENERGYPLUS uses a text input file with a format of *.IDF.

\subsection{Communications between the BES and CFD solvers}

After scaling-up the validated CFD model to match the size of the BES domain, the temperature equation solved in the Reynolds Averaged Navier-Stokes (RANS) scheme in CFD domain. Rather than the steady-state modelling in the validation stage, the CFD domain in the coupling stage were run semi-transiently with weather and boundary conditions updated hourly. The flow velocity and turbulence features derived from experimental data were replaced by vertical wind profiles using the same algorithm as ENERGYPLUS. Here the local wind speed, $U_{z}(\mathrm{~m} / \mathrm{s})$, at altitude, $z(\mathrm{~m})$, is determined by: 


$$
U_{z}=U_{m e t}\left(\frac{\delta_{m e t}}{z_{m e t}}\right)^{\alpha_{m e t}}\left(\frac{z}{\delta}\right)^{\alpha}
$$

where $\alpha$ is a dimensionless exponent and $\delta(\mathrm{m})$ is the boundary layer thickness at the site. Both parameters depend upon the local terrain type. The subscript 'met' refers to those data collected at the meteorological station. Default values of $z_{m e t}, \delta_{m e t}$, and $\alpha_{m e t}$ are $10 \mathrm{~m}, 270 \mathrm{~m}$, and 0.14 , respectively.

In ENERGYPLUS, the embedded equation for the decrease in air temperature with altitude in the troposphere is:

$$
T_{a, z}=T_{b}+L_{a}\left(\frac{E_{r} Z}{\left(E_{r}+z\right)}-H_{b}\right)
$$

where $L_{a}(\mathrm{~K} / \mathrm{m})$ is the air temperature gradient throughout the troposphere, and is always $L_{a}=-0.0065 \mathrm{~K} / \mathrm{m} . E_{r}(\mathrm{~m})$ is the radius of the Earth with a value of $6356 \mathrm{~km} . H_{b}(\mathrm{~m})$ allows the boundary layer to be extended above the troposphere, which is unnecessary here and so is always zero. $T_{a, z}\left({ }^{\circ} \mathrm{C}\right)$ and $T_{b}\left({ }^{\circ} \mathrm{C}\right)$ are the local air temperatures at altitude $z$ and at ground level, respectively. The latter can be determined from the meteorological air temperature $\left(T_{a, z}\right.$ met $)$ measured at height $z_{\text {met }}$ using:

$$
T_{b}=T_{a, z \text { met }}-L_{a}\left(\frac{E_{r} z_{m e t}}{\left(E_{r}+z_{m e t}\right)}-H_{b}\right)
$$

Here, $T_{a, z \text { met }}$ is normally measured at $z_{m e t}=1.5 \mathrm{~m}$ above ground level.

The vertical velocity and temperature gradients at the CFD inlet boundary (see Figure 3a) are determined by Equation (1)-(3), so that both tools have the same profiles. The following equations are used to calculate the local turbulence kinetic energy, $k(\mathrm{~J} / \mathrm{kg})$, and the turbulence dissipation rate, $\varepsilon\left(\mathrm{m}^{2} / \mathrm{s}^{3}\right)$, at $z$ in the vertical profile of the dimensionless turbulent intensity, $I_{z}$ where:

$$
I_{z}=\frac{u_{z}^{\prime}}{U_{z}}=0.1\left(\frac{z}{\delta}\right)^{-\alpha-0.05}
$$

The boundary layer thickness, $\delta(\mathrm{m})$, depends on the local terrain, and is $\delta=460 \mathrm{~m}$ in a city [30]. The corresponding power law exponent is $\alpha=0.33$ for a city, and $u_{z}^{\prime}(\mathrm{m} / \mathrm{s})$ is the root mean square of the velocity fluctuations in the stream-wise direction:

$$
\begin{gathered}
k_{z}=\frac{u_{u, z}^{\prime 2}+u_{v, z}^{\prime 2}+u_{w, z}^{\prime 2}}{2} \cong \frac{3}{2} u_{z}^{\prime 2}=\frac{3}{2}\left(I_{z} U_{z}\right)^{2} \\
\varepsilon_{z}=C_{\mu}^{1 / 2} k_{z} \frac{U_{r e f}}{z_{r e f}} \alpha\left(\frac{z}{z_{r e f}}\right)^{\alpha-1}
\end{gathered}
$$

where $C_{\mu}$ is the dimensionless $k-\varepsilon$ model constant taken as $C_{\mu}=0.09$. The 'ref' subscript indicates reference conditions, where $U_{r e f}$ and $z_{r e f}$ are set using meteorological data.

The value of $h_{c}$ used by the CFD tool is a function of the temperature difference between the solid surface, $T_{s}\left({ }^{\circ} \mathrm{C}\right)$, and the adjacent fluid flow, $T_{a, s}\left({ }^{\circ} \mathrm{C}\right)$. However, ENERGYPLUS calculates the surface convective heat transfer using $T_{a, z}\left({ }^{\circ} \mathrm{C}\right)$, which is considered to have a fixed value at a particular height for any given weather data. The principle of the coupling process is to achieve a unified convective heat flux, $q_{c}^{\prime \prime}$, in both tools. Therefore the parity is achieved by equating the two terms: 


$$
q_{c, C F D}^{\prime \prime}=h_{c}\left(T_{s}-T_{a, S}\right)=h^{*}\left(T_{s}-T_{a, z}\right)=q_{c, B E S}^{\prime \prime}
$$

where $h^{*}$ is a virtual $h_{c}$ that works as an adapter to helps ENERGYPLUS estimate the same convection as the CFD model. It is given by:

$$
h^{*}=\frac{q_{c, C F D}^{\prime \prime}}{\left(T_{s}-T_{a, z}\right)}
$$

In an iterative process (see Figure 2), it can be also presented as:

$$
h_{i+1}^{*}=\frac{q_{c, C F D_{i}}^{\prime \prime}}{\left(T_{s_{i}}-T_{a, z}\right)}
$$

where $i$ specifies the current iteration index.

Table 1 shows boundary conditions set for the coupling simulation.

Table 1 Boundary conditions of CFD domain for coupling simulation

\begin{tabular}{ccc}
\hline Boundary & Type & Treatment \\
\hline \hline Ground & Wall & $\begin{array}{c}\text { No-slip } \\
\text { Constant temperature, }{ }^{*} T g \text { from weather data }\end{array}$ \\
\hline Building surfaces & Wall & $\begin{array}{c}\text { No-slip } \\
\text { Constant Temperature, } T s \text { from BES }\end{array}$ \\
\hline Inlet & Wall & No-slip and adiabatic \\
\hline Outflow & Velocity inlet & $\begin{array}{c}\text { Components specified velocity method: } \\
\text { Velocity components, } \mathrm{x} \text { and y from the vertical profile } \\
k \text { and } \varepsilon \text { from the vertical profile } \\
\text { Temperature from the vertical profile }\end{array}$ \\
\hline Pressure outlet & $\begin{array}{c}\text { Gauge pressure }=\text { Opa } \\
k \text { and } \varepsilon \text { from the vertical profile } \\
\text { Temperature from the vertical profile }\end{array}$ \\
\hline
\end{tabular}

${ }^{*}$ Note: $T g$ is the ground temperature from the weather data file.

\subsection{CFD modelling}

The governing equations of the RANS scheme for the steady modelling are, for continuity and momentum, respectively:

$$
\begin{gathered}
\frac{\partial}{\partial x_{j}}\left(U_{j}\right)=0 \\
\rho U_{j} \frac{\partial}{\partial x_{j}}\left(U_{i}\right)=-\frac{\partial P}{\partial x_{i}}+\frac{\partial}{\partial x_{j}}\left[\mu\left(\frac{\partial U_{i}}{\partial x_{j}}\right)+\left(-\rho \overline{u_{\imath} u_{\jmath}}\right)\right]
\end{gathered}
$$

where $U(\mathrm{~m} / \mathrm{s})$ is the mean flow velocity, $u$ is the dimensionless fluctuating component of $U, P(\mathrm{~Pa})$ is the fluid pressure, $\rho\left(\mathrm{kg} / \mathrm{m}^{3}\right)$ is the fluid density, $\mu$ is the dimensionless molecular viscosity, and the $-\rho \overline{u_{\imath} u_{J}}$ term is the Reynolds stress tensor, which can be determined by the eddy viscosity assumption:

$$
-\rho \overline{u_{\imath} u_{\jmath}}=\mu_{t}\left(\frac{\partial U_{i}}{\partial x_{j}}+\frac{\partial U_{j}}{\partial x_{i}}\right)-\frac{2}{3} \delta_{i j}\left(\mu_{t} \frac{\partial U_{k}}{\partial x_{k}}+\rho k\right)
$$

where $\mu_{t}(\mathrm{~kg} / \mathrm{m} \cdot \mathrm{s})$ is the eddy viscosity. 
In this study, the $k-\varepsilon$ model, which solves transport equations for $k$ and its dissipation rate, is used to calculate $\mu_{t}$ by

$$
\mu_{t}=C_{\mu} \rho \frac{k^{2}}{\varepsilon}
$$

where $C_{\mu}=0.09$ is a constant number.

Standard $k-\varepsilon$ method was selected to solve turbulence model [31]. This turbulence model is widely used in similar studies due to its low computational burden when compared to the more accurate Large-Eddy Simulation (LES) method.

\subsubsection{Computational domain for validation}

The configuration of the CFD model needs to be validated against empirical data before being applied to the coupling method. The experiments by the Architectural Institution of Japan (AIJ) [32] provides data measured in a wind tunnel for a range of cuboids and layouts. Its Case $C$ consists of nine small cubes arranged in a $3 \times 3$ array and represents a simple city block, and was selected as the benchmark for the CFD model validation. The aspect ratio of every street canyon in Case $\mathrm{C}$ was unity.

A directionally-independent circular model proposed by Mirzaei and Carmiliet [33] was employed to capture the stochastic winds, as shown in Figure 3a. According to the best-practice guidance given by COST [34], the computational domain had dimensions of $5 \mathrm{H}$ and $15 \mathrm{H}$ in the vertical and horizontal planes, respectively. Here, $H$ is the height of the target objects and is $H=0.2 \mathrm{~m}$. The inflation ratio of continuous cells was maintained, so that it was no larger than 1.2. To minimize the computational cost of the coupling process, hybrid meshes were generated using the multi-zonal pave method in FLUENT 17.2@. A dense layer of structured hexahedral grids was drawn around the buildings and a coarse layer of structured grids was created towards laterals of the site domain. Two structured layers were linked by an unstructured buffer layer with a smooth transition. This meshing strategy was aimed to reduce the computational cost with a minimal impact on the accuracy [35]. Figure $3 b$ shows that the buffer layer was filled with dense unstructured hexahedral cells. The perimeter of circle was evenly divided into 16 parts, so that the domain boundaries can capture different wind directions at intervals of $22.5^{\circ}$; see Figure $3 a$. Four meshes consisting of 130,968, 159,469, 198,627, and 233,766 cells, were created with a refinement ratio of 1.1 in each dimension following the COST recommendations [34].

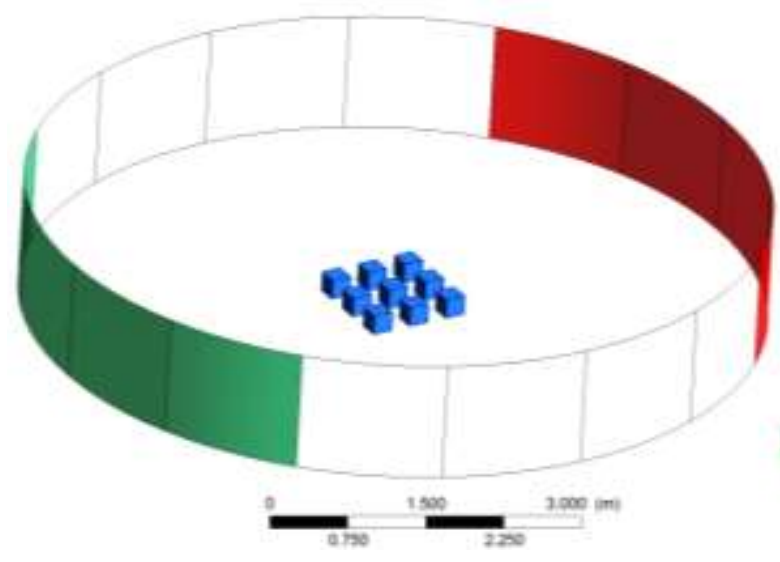

(a)

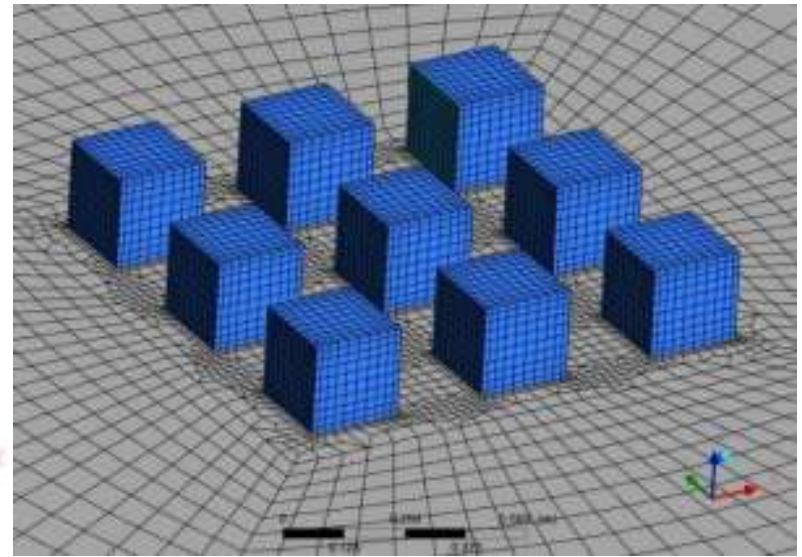

(b)

Figure 3 a) Computational domain (green, inlet boundary; red, outlet boundary; white, lateral boundary) and b) computational grids for AlJ-Case-C CFD validation 
The vertical profiles of the inflow velocity $\left(U_{z}\right)$, the kinetic energy $\left(k_{z}\right)$, and the turbulence dispersion rate $\left(\varepsilon_{z}\right)$ were obtained from the AIJ wind tunnel measurements. A standard function was applied as the wall treatment. All of the equations were solved by the SIMPLE algorithm. The pressure equation was discretized using a second order scheme whilst the rest used the second order upwind method. Convergence was achieved below six orders of magnitude for all equations, except for the continuity equation, which was $<5 \times 10^{-6}$.

\subsubsection{Quantified evaluation of the model performance for the validation study}

The prediction error is given by Equation (14). Two more dimensionless metrics were introduced to quantify the performance of the computational model, including the hit rate $\left(q_{h r}\right)$ and the fraction of predictions within a factor of two of observations ( $F A C 2)$. These metrics are used to compare the experimental (observed and denoted as $o$ ) and numerical (predicted and denoted as $p$ ) values of a given variable for all $N$ data points

$$
E_{1}=\frac{1}{N} \sum_{i=1}^{N}\left|\frac{p_{i}-o_{i}}{o_{i}}\right|
$$

where $i$ denotes the index of samples, ranging from 1 to $N$.

The hit rate is given by

$$
q_{h r}=\frac{1}{N} \sum_{i=1}^{N} n_{i} \text { with } n_{i}=\left\{\begin{array}{l}
1 \text { for }\left|\frac{p_{i}-o_{i}}{o_{i}}\right| \leq D_{q_{h r}} \text { or }\left|p_{i}-o_{i}\right| \leq W_{q_{h r}} \\
0 \text { else }
\end{array}\right.
$$

where $D_{q_{h r}}$ is the allowed relative deviation. The threshold for the absolute deviation $\left(W_{q_{h r}}\right)$ is related to the experimental uncertainty, which can be estimated from the engineering data, by the equipment manufacturer, or empirically from other experiments that use the same experimental method [36]. In this study, the thresholds for $D_{q_{h r}}$ was set as 0.25 , following COST [37], and $W_{q_{h r}}$ was set as 0.03 [38].

FAC2 is considered to be one of the most robust methods because it excludes the high influence of extreme outliers [37, 39]. FAC2 can be determined by

$$
F A C 2=\frac{1}{N} \sum_{i=1}^{N} n_{i} \text { with } n_{i}=\left\{\begin{array}{l}
1 \text { if } 0.5 \leq \frac{p_{i}}{o_{i}} \leq 2.0 \\
0 \text { else }
\end{array}\right.
$$

A model that shows a perfect agreement to an experiment would have $q_{h r}$ and FAC2 equal to 1. Chang and Hanna [39] claimed that a model with FAC2 over 0.5 would be good enough whereas COST [37] required a no-less-than 0.66 hit rate for a successful velocity-field validation.

\section{Results}

\subsection{Validation of airflow model}

The velocity field of CFD model was validated using the AIJ experimental data and procedures described in Section 2. To study the boundary layer effect inside the street canyons, comparisons were made at set of 120 measurement points located at $0.02 \mathrm{~m}$ above the ground. A velocity obtained by CFD prediction was with respect to the time-averaged vector $\left(U_{z, C}\right)$ and it was converted to averaged instantaneous scalar velocity $\left(U_{z}^{*}\right)$ as recommended by [40]. 


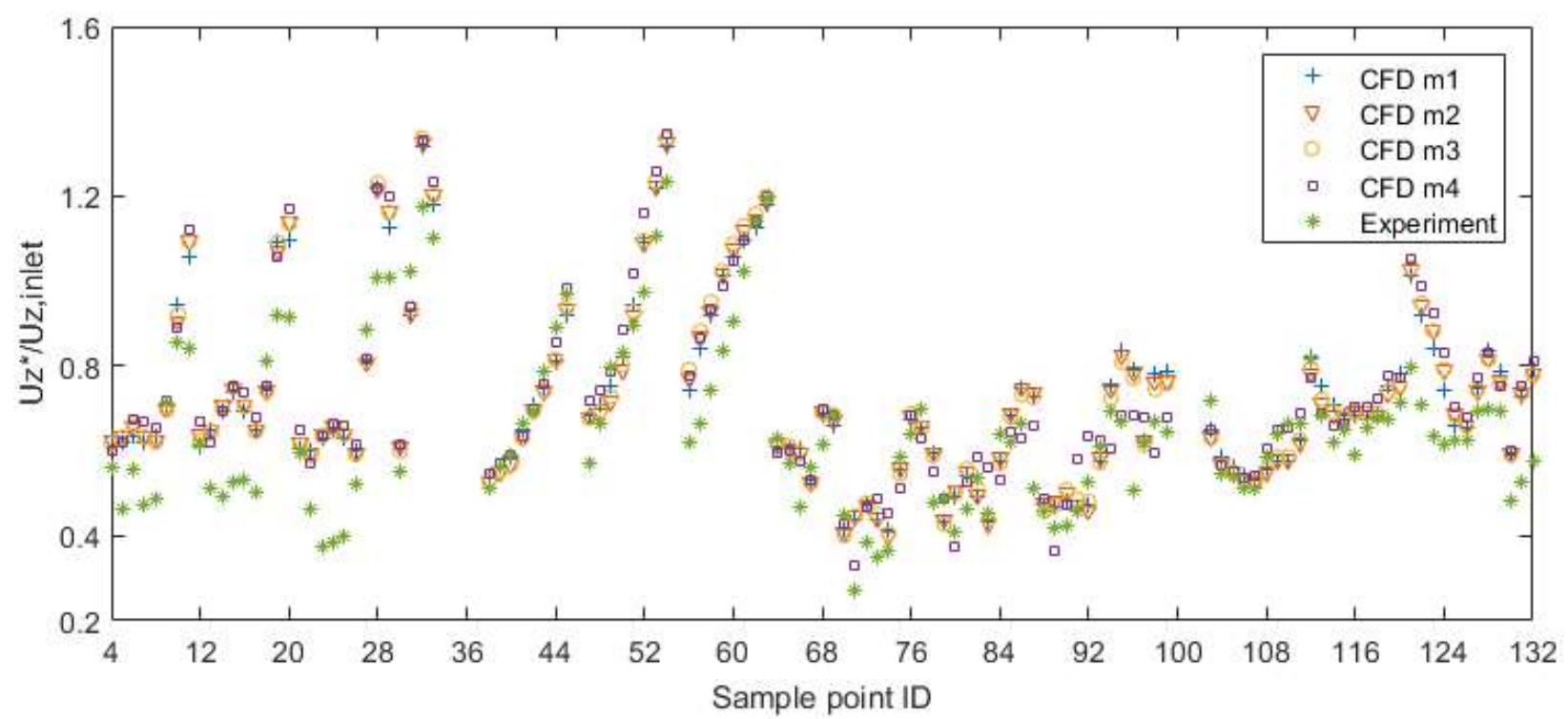

Figure 4 Comparison of numerical and experimental normalized velocity at each sample point

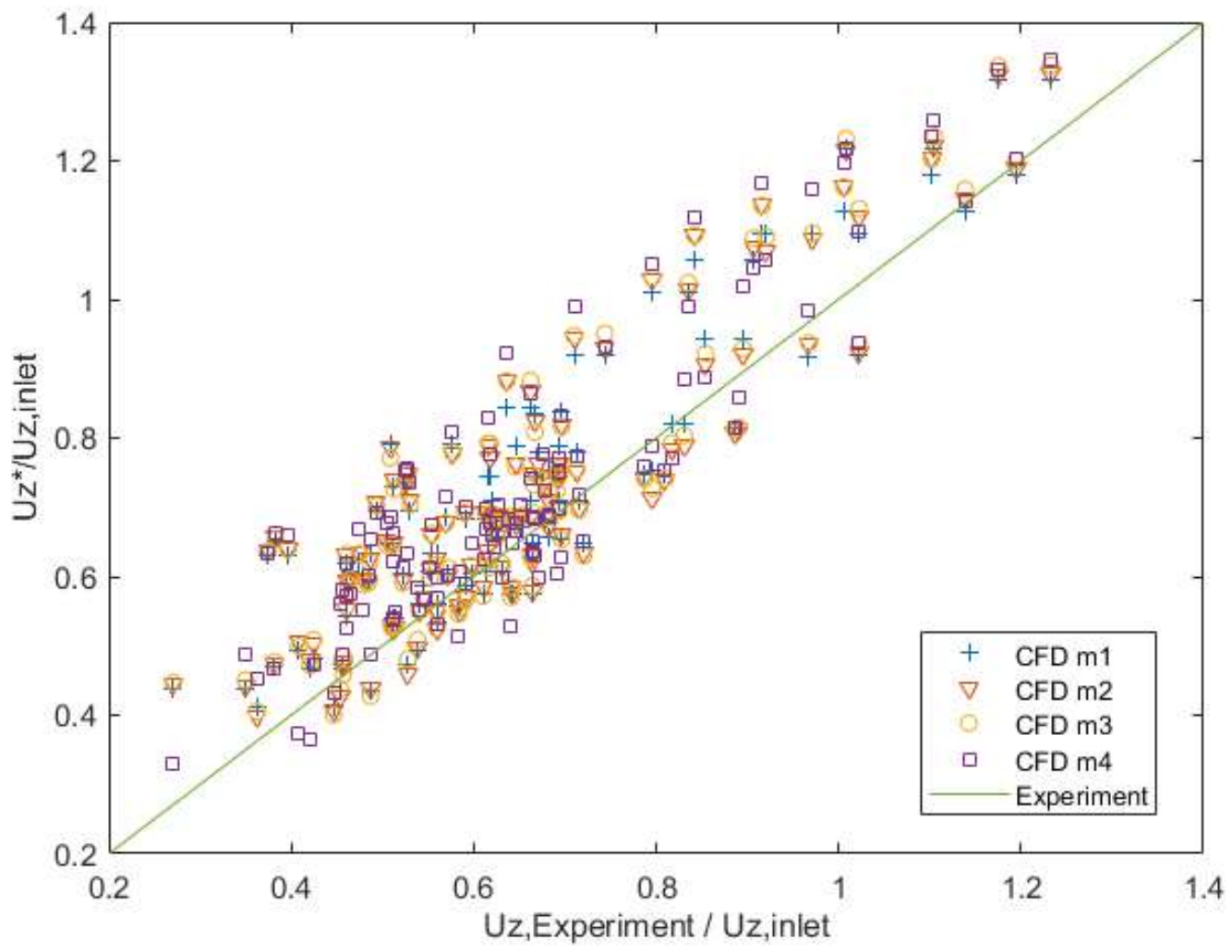

Figure 5 Plot of normalized velocity versus normalized experimental velocity

The predicted values of $U_{z}^{*}$ were compared to the wind tunnel measurements in the format of normalized velocity with respect to the inlet velocity $U_{z \text {,inlet }}$ at the test height $(2.434 \mathrm{~m} / \mathrm{s})$ used in the AlJ Case C scenario. The four meshes created with increased model size (see Section 2.3.1) are hereon denoted $\mathrm{m} 1, \mathrm{~m} 2, \mathrm{~m} 3$ and $\mathrm{m} 4$. Figure 4 shows the comparison at each sample point. Large discrepancies were observed, particularly close to the blocks in the street canyons. This is due to a failure in, or weakness of, the selected turbulence-model at representing the turbulent kinetic energy in the boundary layer immediately adjacent to the solid cubes [41]. The overestimation of the velocity field by the standard $k-\varepsilon$ turbulence model is a well-known and is shown by Figure 5 where a majority of data points lie above the straight line (with a gradient of unity), which indicates experimental and 
prediction parity. Figure 6 shows the minimum, maximum, $25^{\text {th }}$ and $75^{\text {th }}$ percentiles, median and mean (no considering the outliers that exceed 1.5 times the interquartile range away from the $25^{\text {th }}$ and $75^{\text {th }}$ percentiles) of error $E_{1}$ and Table 2 quantifies the accuracy of each model by providing the $95^{\text {th }}$-centile, $5^{\text {th }}$-centile, median and mean of $E_{1}$, the hit rate, and FAC2; see Equations (14)-(16) in Section 2.3.2. The $5^{\text {th }}$-centile $E_{1}$ of the models were within $0.005-0.020$, which was good. The $95^{\text {th }}$-centile error exceeded 0.3 for each model. However, such poor conditions are considered to be rare and extreme due to the low median value, which was approximately 0.1 . The mean error of all created models was around 0.13 , which is an acceptable value [33].

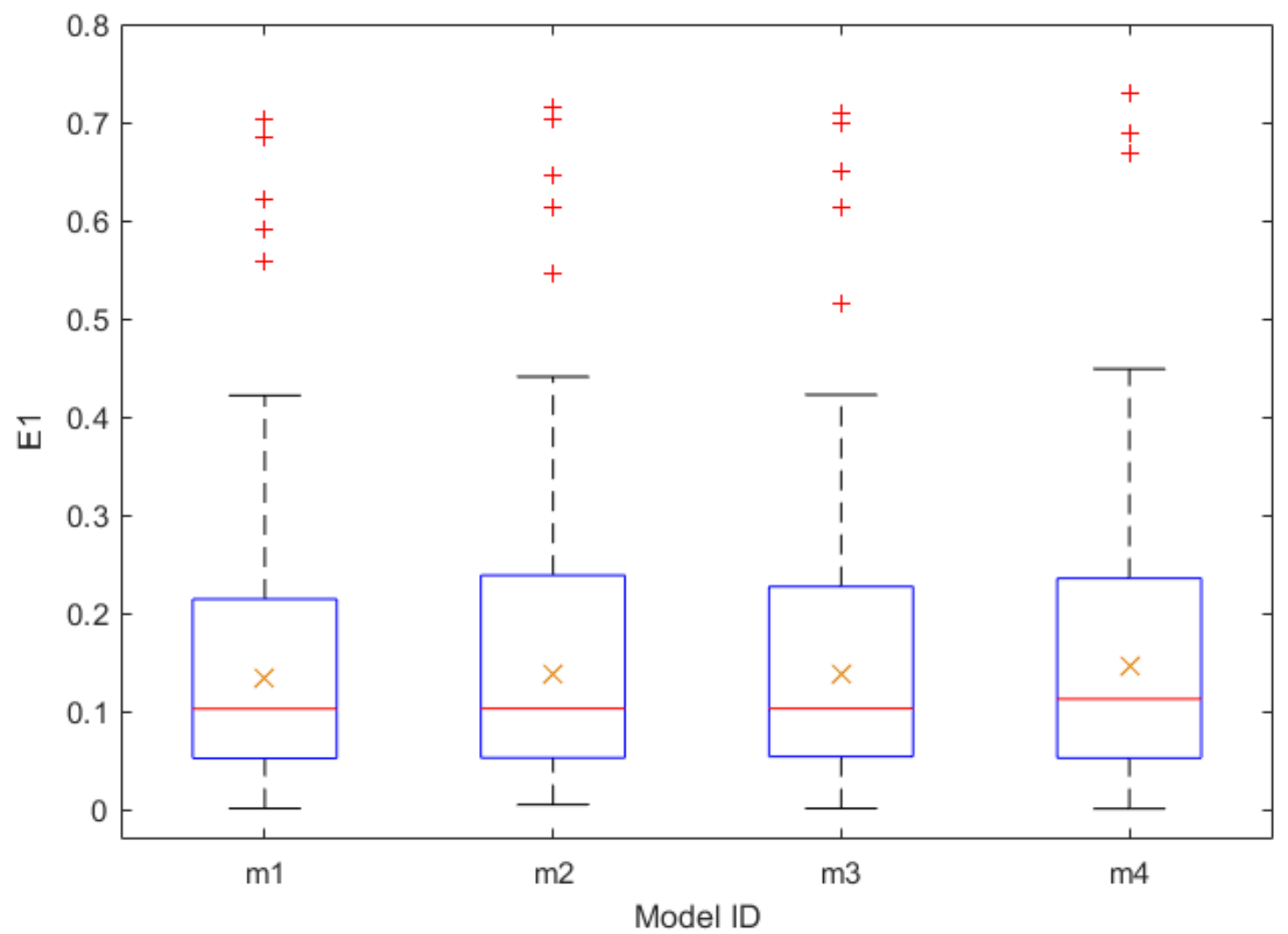

Figure 6 Plot of $E_{1}$ of different CFD models (blue box, interquartile range; red horizontal line, median; yellow cross, mean; black bars, minimum and maximum; red cross, outliers)

Table 2 Assessment of CFD model performance using three metrics

\begin{tabular}{ccccc}
\hline \hline Model ID & $\mathrm{m} 1$ & $\mathrm{~m} 2$ & $\mathrm{~m}$ & $\mathrm{~m} 4$ \\
\hline \hline $9^{\text {th }}$ percentile $\mathrm{E}_{1}$ & 0.3312 & 0.3566 & 0.3569 & 0.3961 \\
\hline $5^{\text {th }}$ percentile $\mathrm{E}_{1}$ & 0.0107 & 0.0168 & 0.0152 & 0.0056 \\
\hline Median $\mathrm{E}_{1}$ & 0.1026 & 0.1003 & 0.0938 & 0.1104 \\
\hline Mean $\mathrm{E}_{1}$ & 0.1338 & 0.1385 & 0.1379 & 0.1456 \\
\hline Hit rate, $q_{h r}$ & 0.792 & 0.783 & 0.775 & 0.783 \\
\hline FAC2 & 1.000 & 1.000 & 1.000 & 1.000 \\
\hline \hline
\end{tabular}

Table 2 shows that the hit rates for all the models are over 0.77 , which is much higher than 0.66 baseline criterion, which COST [37] suggests indicates a successful validation of the mesh; see Section 2.3.2. The FAC2 values were 1 for all models, suggesting that there was no extreme outlier (half or twice the empirical data) in the predictions. Furthermore, they all surpass the benchmark value of 0.5 proposed by Chang and Hanna [39] as good enough. In general, the metrics show that the 
performance of the four models was similar. This may be because the heights of their first layers' cells are identical. Moreover, the sample points were selected at locations close to ground level, which is also near the location of this first layer wall-function, and could be one of the main sources of error besides the turbulence model. The wall $\mathrm{y}^{*}$ of each model was controlled within the range of 30-300 for the implemented standard wall-function, as suggested by [42]. The error barely changed with increasing density, which means the meshes were independent.

These results suggest that model $\mathrm{m} 1$ can now be applied to a case study because its predictions are comparable with models $\mathrm{m} 2-4$, but it has the benefits of being the smallest and having the lowest computational cost.

\subsection{Case Study application of the airflow model}

\subsubsection{Benchmark commercial building from DoE}

It is difficult to find suitable buildings that are a geometric match with the AlJ Case C. An alternative method is to use an existing model of a similar scenario and then amend it to obtain equivalent performance. In this study, a benchmark building is developed from a small office model provided by U.S. Department of Energy (DoE) [43, 44].

The building consists of an attic space and 5 offices laid out, so that one office forms a central core room surrounded on all sides by the other four offices. The window to wall ratio is $24.4 \%$ for the building's south-facing front façade (where the entrance door is situated; see Figure 6) and $19.8 \%$ for the other walls. The door height is $2.13 \mathrm{~m}$, windows occupy $39.7 \%$ of the wall in the horizontal dimension, and $50 \%$ of the area in the vertical one. Windows are located $0.9 \mathrm{~m}$ above ground level. The door width is $6.6 \%$ of the wall width.

The building is occupied between 7am to 9pm on weekdays, except for national holidays. The percentage occupancy increases to $95 \%$ at 9am. There is a one-hour lunch break between $12 \mathrm{pm}$ and $1 \mathrm{pm}$ when $50 \%$ of the occupants stay in the building. Occupancy decreases to $30 \%$ at $5 \mathrm{pm}$ and then to $10 \%$ at $7 \mathrm{pm}$. The operative temperature is maintained between $21-24^{\circ} \mathrm{C}$ during occupied hours and between $15.6-26.7^{\circ} \mathrm{C}$ at all other times.

The algorithm for the outside surface convection used by the benchmark model is DOE-2, which calculates convective heat transfer coefficient through the equations involving parameters surface roughness, surface tilt from the horizon and two factors depending on if the surface is relatively windward or leeward, referred to [30].

\subsubsection{New model for the neighbourhood case study}

A small street community consists of nine cuboid commercial buildings $(\mathrm{L} \times \mathrm{W} \times \mathrm{H}=10 \mathrm{~m} \times$ $10 \mathrm{~m} \times 10 \mathrm{~m}$ ) in a $3 \times 3$ array. The distance between any two buildings is $10 \mathrm{~m}$, which means that the aspect ratio of every street canyon inside the community is 1 , which agrees with AlJ Case C. Each building is divided into three storeys and the heights of the floors are $3.4 \mathrm{~m}, 3.3 \mathrm{~m}$ and $3.3 \mathrm{~m}$ from the bottom of the building to the top. Windows are situated on the south and north façades of each floor to facilitate cross-ventilation and have the same window to wall ratio used by the benchmark case. Every building has an entrance door in the south façade. The door has a height of $2.13 \mathrm{~m}$ which is the same as that in reference model, but its width is $1 \mathrm{~m}$ because using the $6.6 \%$ of the wall width gave a width that is too narrow. The buildings are oriented to the south to optimize energy conservation and indoor comfort. 


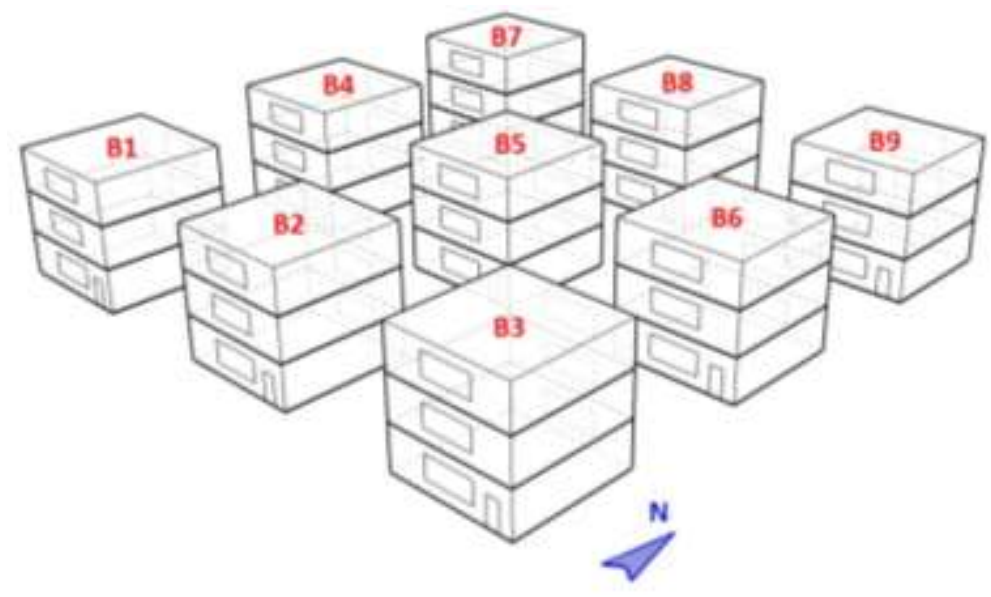

Figure 7 Nine-cube ENERGYPLUS model from south-east view

The shape and dimension of buildings were adjusted to achieve a homologous geometry similar to the CFD domain ( $3 \times 3$ array of nine cubes). The operating conditions in these buildings is functionally similar to the benchmark case, but is simplified; for example, the ideal load of the air system is used instead of the complex PSZ-air conditioning units with a gas furnace system (used in the reference model) for simplification and conservation of computational cost. Figure 7 shows the newly developed ENERGYPLUS models for the case study and provides the nine buildings indexed from B1 in the southwest to B9 in the northeast.

Hourly weather data from the online database [45], shows that the $25^{\text {th }}$ of September is the hottest work day of the year in Los Angeles and is used to assess the indoor environment in the commercial building. The daily temperature ranges from $18.1^{\circ} \mathrm{C}$ to $34.1^{\circ} \mathrm{C}$. Sunset is at $6 \mathrm{pm}$, after which there is no solar radiation until sunrise the next morning. At the preliminary design stage, the DOE-2 algorithms were applied to calculate the outside-surface convection coefficients for a few hours on $24^{\text {th }}$ of September (the day before the modelled day), and also for the initial guesses of each hour on $25^{\text {th }}$ September, the simulation day.

\subsection{Coupling Simulation Results}

Convergence of the coupling process can be determined by two methods. The first is when the residual of $T_{s}$ by BES or $h_{c}$ by CFD between two iterations reaches a threshold. The second method is to achieve acceptable difference in $q_{c}^{\prime \prime}$ between two domains. In this study, the first method was employed and the convergence criterion for each time-step of the coupling process was set to three orders of magnitudes for both $T_{s}$ and $h^{*}$. However, the convergence criterion was altered to two orders of magnitudes if the number of iterations for a single time-step exceeded 20, and is deemed an acceptable compromise between prediction accuracy and computational time and cost. The residuals were determined using the average error between two sequential iterations. As ENERGYPLUS only accepts user-defined CHTC for non-fenestration surfaces, all of the iterative analysis and results given in the following sections are based on exterior walls and roofs.

\subsubsection{One-time-step dynamic coupling}

Fully dynamic coupling is a combination of a series of the one-step-time dynamic couplings. In this study, a daily simulation was performed that contains 24 one-step-time couplings. Figure 8 shows the residuals of $T_{s}$ and $h^{*}$ for the first hour of the $25^{\text {th }}$ of September as an example of the convergence process. The residuals are displayed logarithmically to base 10 to aid interpretation. According to 
meteorological data, the ambient air temperature is $19.4^{\circ} \mathrm{C}$, and the prevailing wind direction is from $50^{\circ}$ (clockwise from due North) at a speed of $3.1 \mathrm{~m} / \mathrm{s}$.

In this time step, the average convective heat energy gained by the exterior surfaces (including all fenestration surfaces) are changed by approximately $64 \%$. The average change of the daily community convective energy is found to exceed $82 \%$. Figure 9 compares the initial surface temperature contours of each building with the fully converged contours. It shows that higher $T_{s}$ are predicted using the coupled method. Also, the fully converged results clearly show the discrepancies inside the community due to the sheltering effect. Figure 10 shows the number of iterations used to achieve convergence between two domains for each hour. The residual criterion between two programs for each time-step is guaranteed to be $<1 \times 10^{-3}$. However, some situations could occur where the convergence criterion needs to be relaxed when the residuals decline slowly with regular temperature oscillations and fail to approach the level of $1 \times 10^{-3}$ within 20 iterations. Then, the criterion is increased to $1 \times 10^{-2}$ to minimize computational time.

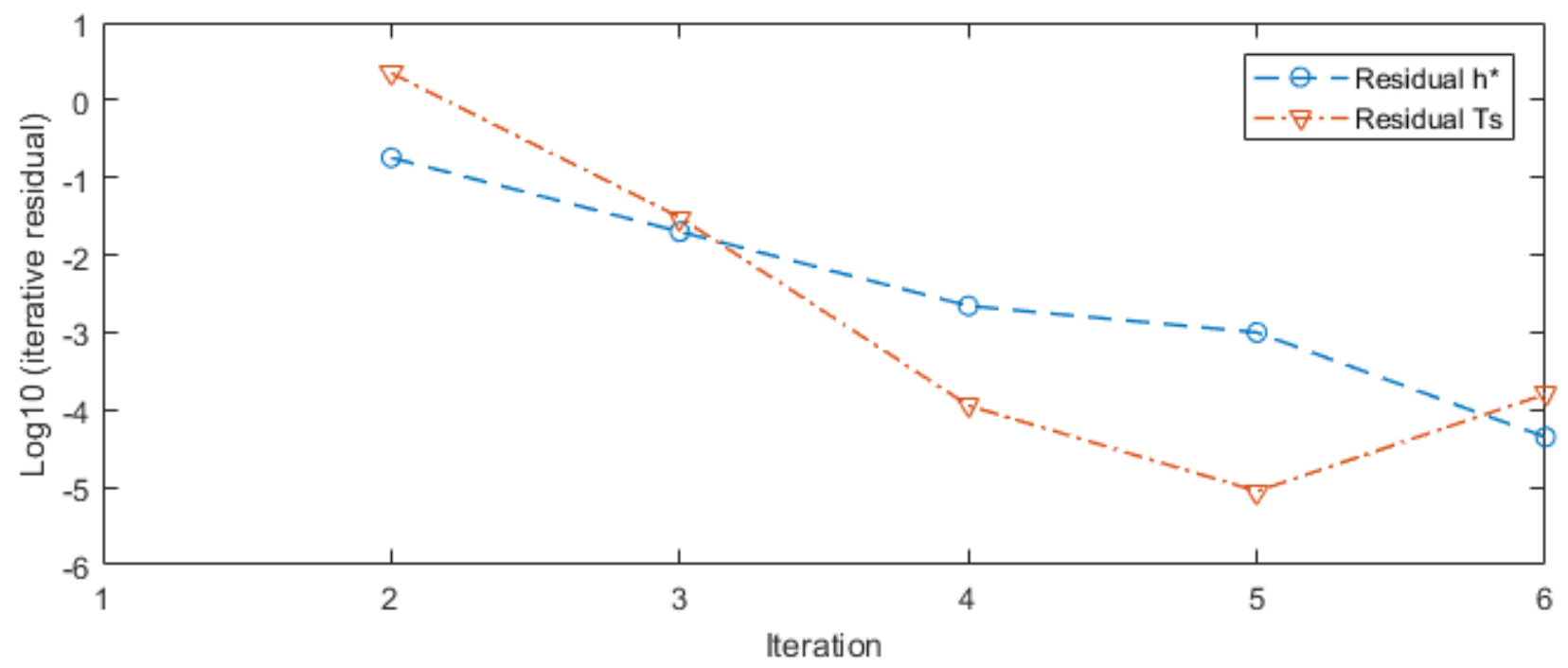

Figure 8 Example of convergence of BES-CFD iterative calculations in the first hour of $25^{\text {th }}$ of September

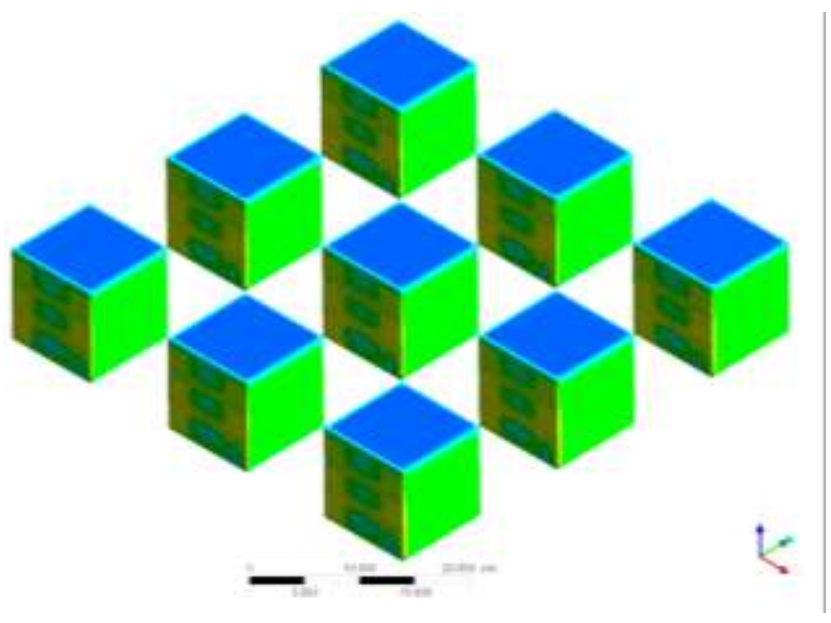

$\mathrm{a}(1)$

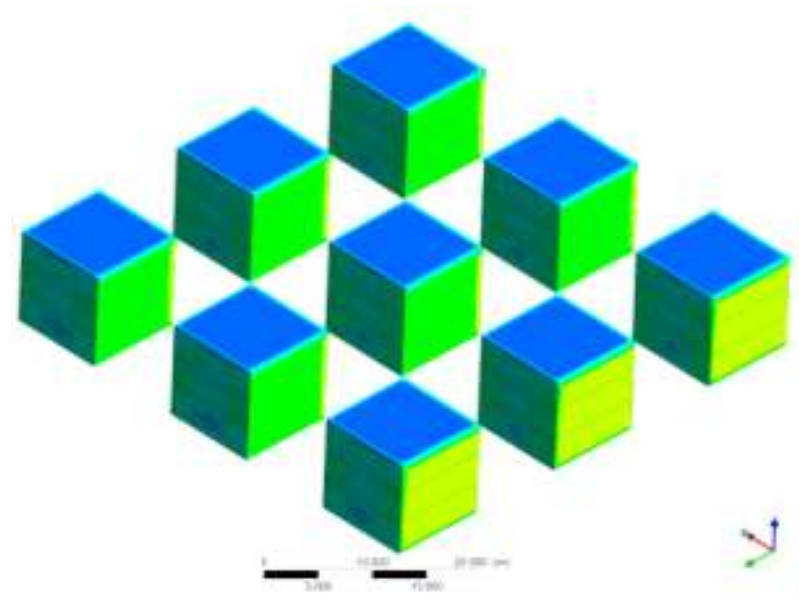

$\mathrm{a}(2)$ 


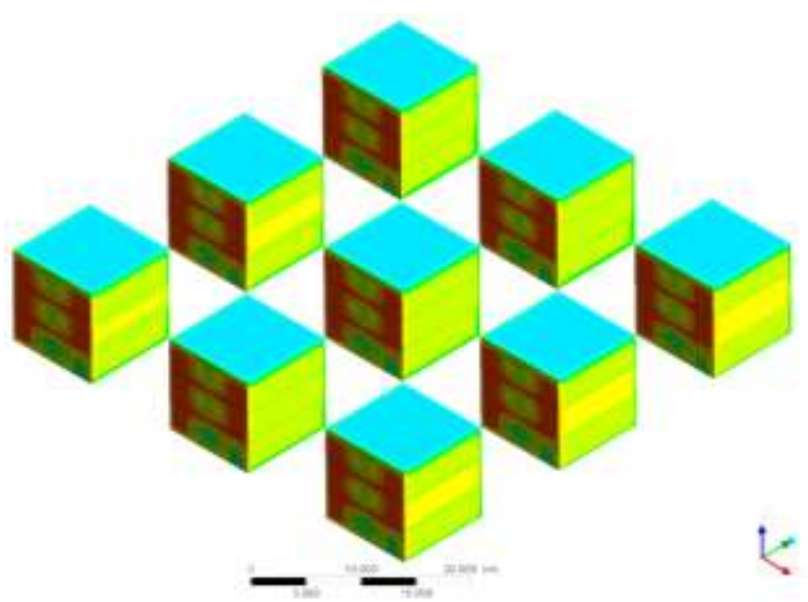

$b(1)$

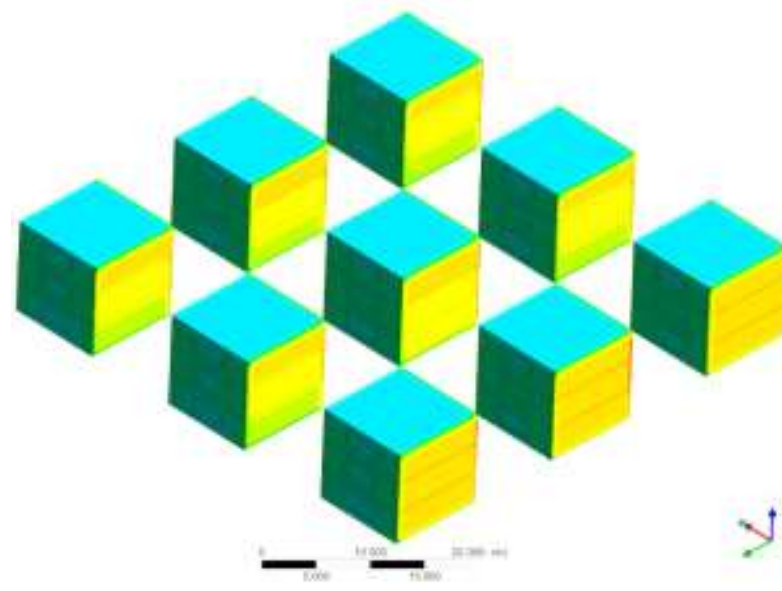

$\mathrm{b}(2)$

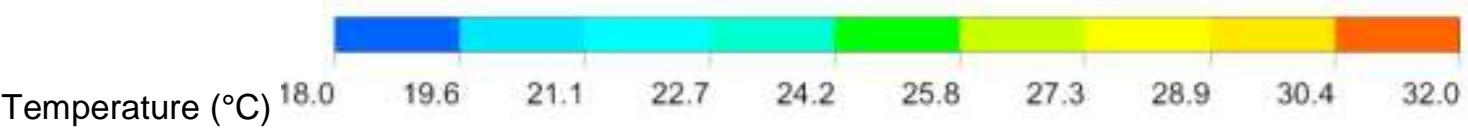

Figure 9 Building surface temperature contours in the first hour of test day at a) $1^{\text {st }}$ iteration (by ENERGYPLUS only) and b) last iteration (converged after coupling) in 1) southeast and 2) northwest view

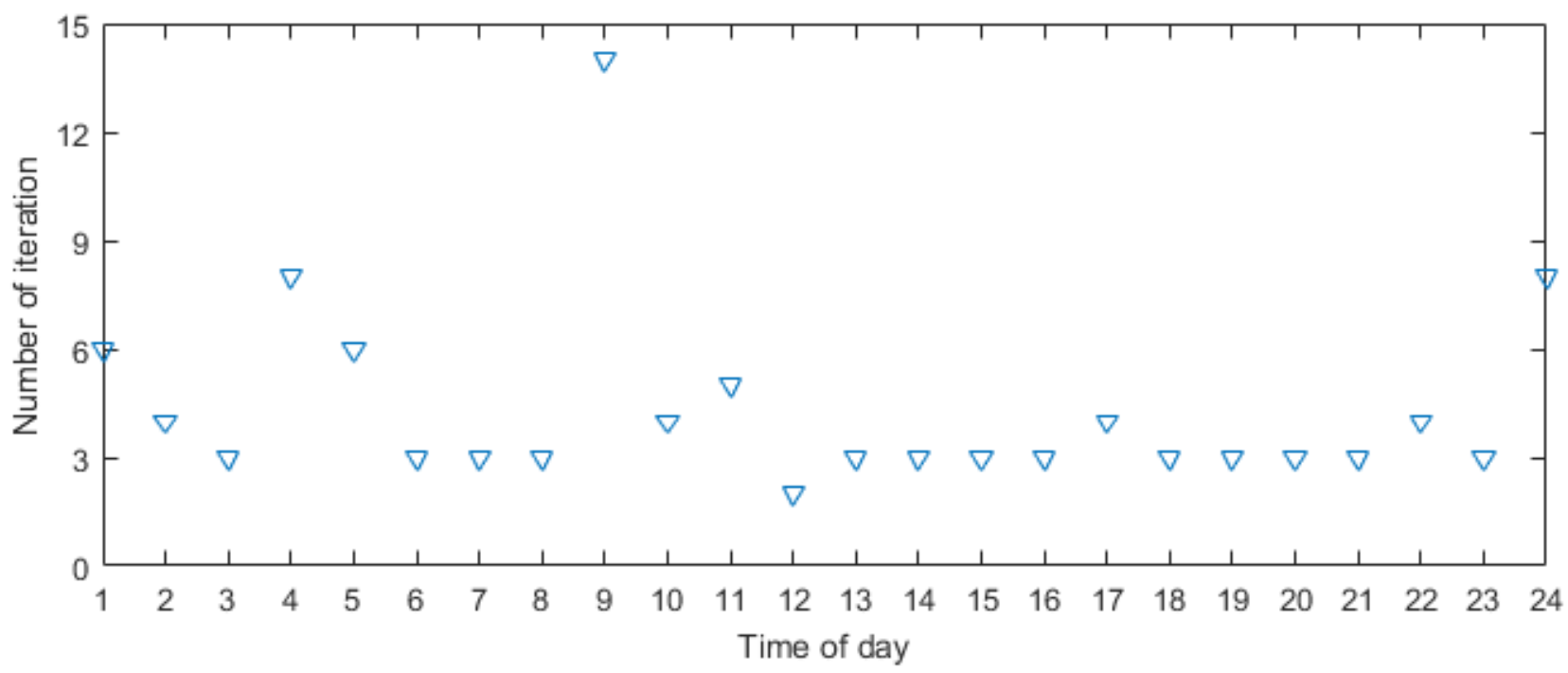

Figure 10 Number of iterations for convergence of the hourly basis coupling

\subsubsection{Sheltering effect inside neighbourhood community}

In ENERGYPLUS, the effect of the wind direction is taken into account by classifying walls as either windward or leeward, even in some advanced algorithms, such as TARP, MoWiTT and DOE2. The differences between the buildings' energy estimations caused by sheltering effect were small when calculated by these algorithms. Using an airflow analysis produced by CFD, this aspect can be significantly improved. We now use the buildings denoted B1, B2, B3 and B5 (see Figure 7) as case study examples during the first hour of the simulation, when the wind comes from northeast. Here, B3 is the windward building, B1 is the farthest building from the wind source and B5 is located in the centre of the array; see Figure 7.

Figure 11 shows the rate of convective heat gain per unit area of each surface for the first hour of the day when the influences of solar radiation and shadow distribution can be eliminated. Each surface is denoted using the format: storey number-surface type-surface orientation. Here, $S$ and $R$ represent walls and roofs, respectively. Then, orientation is counted counter-clockwise from due south 
as 1 (e.g. 1S2 denotes the east wall on the ground floor). In general, there are no significant discrepancies between the initial values of $q_{c}^{\prime \prime}$ used by ENERGYPLUS for surfaces on the selected four buildings facing in the same direction. The average standard deviation of $q_{c}^{\prime \prime}$ obtained by the coupled method for each surface of the nine buildings is 0.805 , which is much lower comparing to 4.393 obtained for the converged coupling results during the first hour of the day. The latter value enhances the representation of the sheltering effect between the neighbourhood blocks as seen in Figure 11 and Figure 12. Figure 12 clearly shows a much higher standard deviation for the community $q_{c}^{\prime \prime}$ using the coupled method than that obtained using the DOE-2 algorithm embedded in ENERGYPLUS. The sheltering effect is clearest at $S 2$ (east surface) on each floor obtained by the coupled method and is less dominant in S4 (west surface). In addition, the standard deviations of $q_{c}^{\prime \prime}$ at S1, S2 and S3 at each floor are very similar, but only that for S4 is found to be higher when calculated by ENERGYPLUS. In contrast, clear differences can be seen in the results obtained by the coupled method.

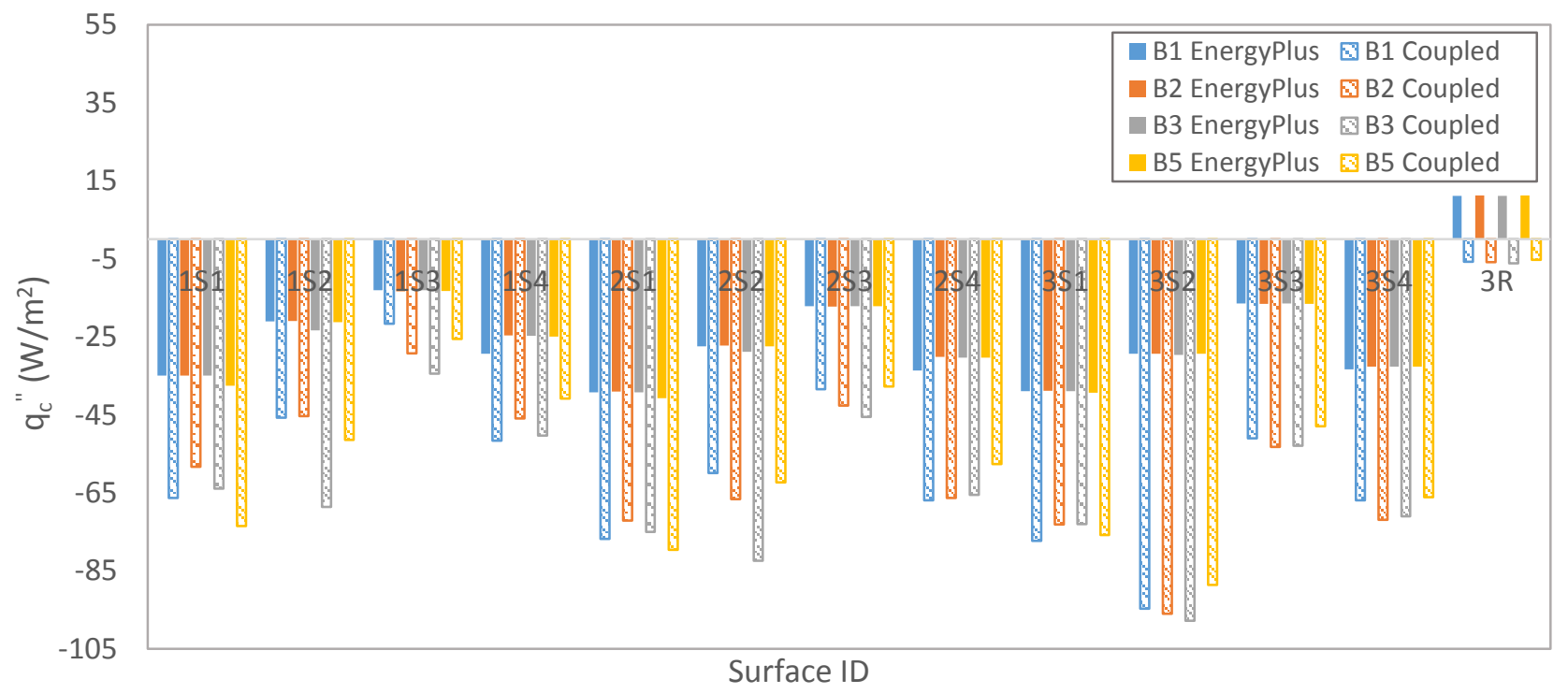

Figure 11 Comparison of $q_{c}^{\prime \prime}$ of B1, B2, B3 and B5 exteriors surfaces in the $1^{\text {st }}$ hour of the test day

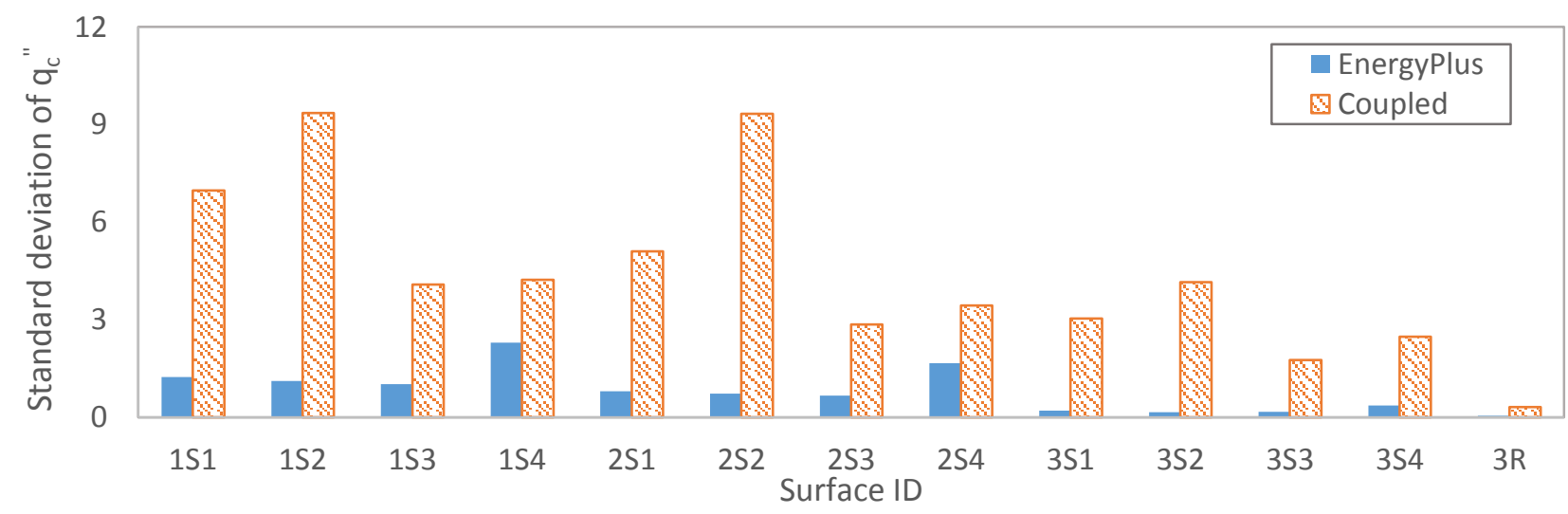

Figure 12 Standard deviation of the community convective energy at different surfaces in the $1^{\text {st }}$ hour of the test day 


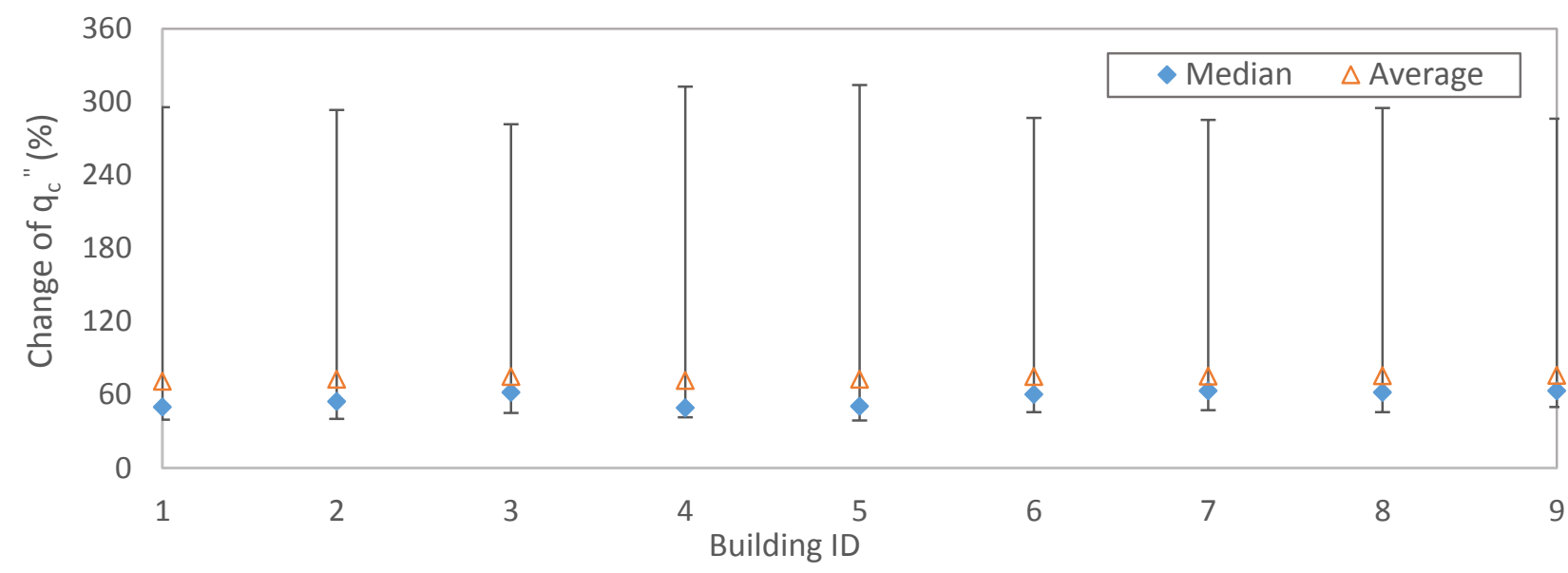

Figure 13 Improvement in $q_{c}^{\prime \prime}$ at exterior rough surfaces by the coupling CFD-BES method in the $1^{\text {st }}$ hour of the test day

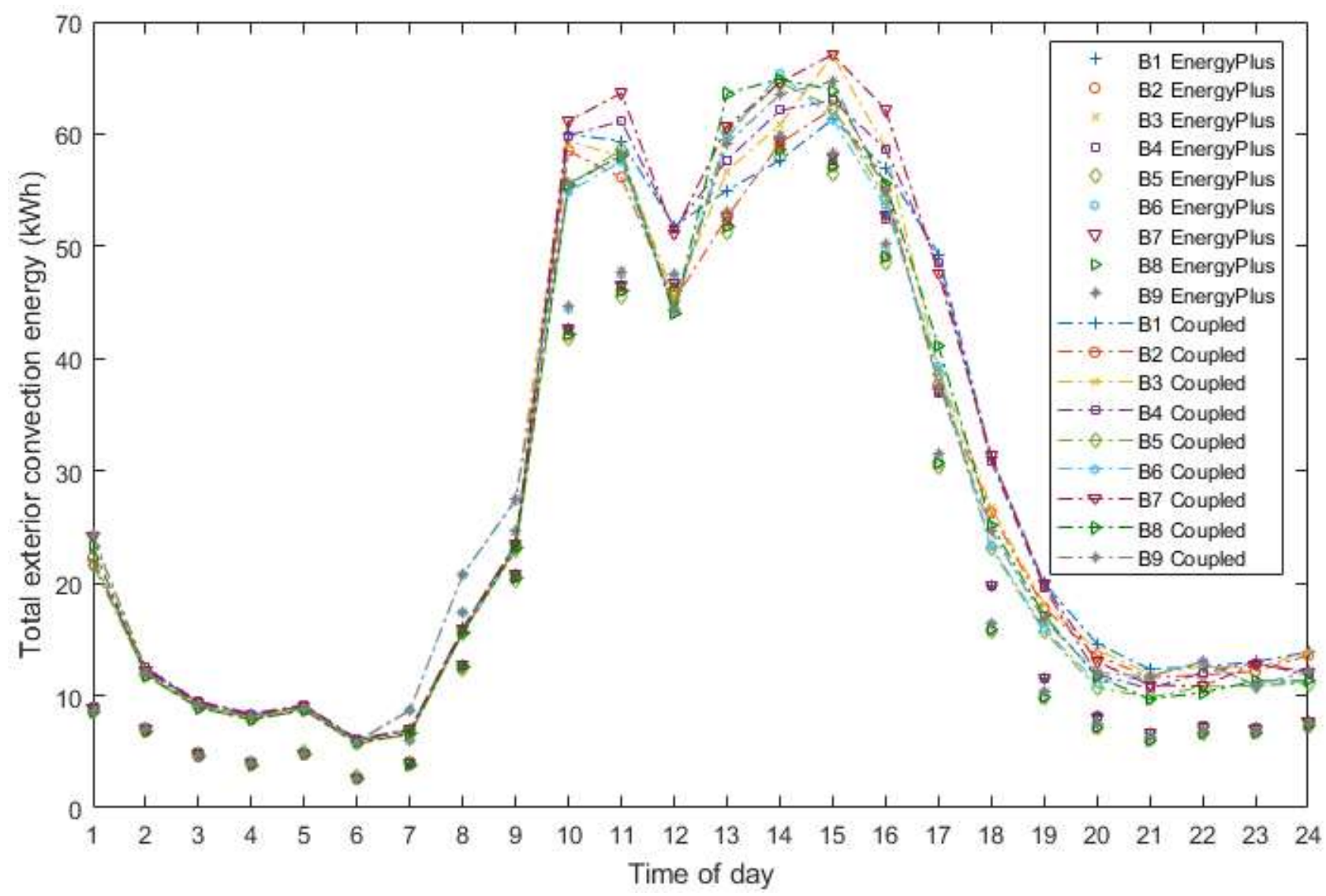

Figure 14 Total hourly exterior surface convective energy of buildings by DoE-2 (initial) and the coupled method

Figure 13 shows the maximum, minimum, median and average prediction enhancements of $q_{c}^{\prime \prime}$ for each building during the first hour of the simulation day. The change in $q_{c}^{\prime \prime}$ for an individual surface can be up to $313 \%$. All the mean values are larger than the corresponding median values for each building, which means that most surfaces have been changed by a higher value than the mean. In general, windward buildings (B3, B6 and B9) are more sensitive to the proposed coupling method. During this hour, the average improvement of $q_{c}^{\prime \prime}$ at exterior rough surfaces is approximately $74 \%$. Although there is no direct access to amend the CHTC values of fenestration surfaces, they are modified somehow due to the improved values for the facades they are located in. Figure 14 compares the total hourly convective energy of each building's exterior surface during the simulation 
day predicted using DOE-2 and the coupling method. The dash lines indicate the DOE-2 algorithm and are clearly very concentrated while the reasons for the discrepancies are unclear.

\subsubsection{Comparison of embedded CHTC algorithms and coupling method}

After completing the fully dynamic coupling for the simulation day, the newly created dynamic CHTC profiles are compared to those obtained using the algorithms embedded in ENERGYPLUS, including DOE-2, TARP, MoWiTT, SimpleCombined and the Adaptive model. Figure 15 shows the average change of the CHTC throughout the simulation day for each building by percentage. The deviation from SimpleCombined is much higher than the others, especially for buildings B5, B6, B8 and B9. The highest discrepancy between the SimpleCombined CHTC and the coupled CHTC of an individual surface throughout the test day is over $521 \%$. The absolute average discrepancy between the SimpleCombined and the coupled results is up to $7.95 \mathrm{~W} / \mathrm{m}^{2} \mathrm{~K}$. DOE-2 is found to provide the most similar predictions to the coupled model while the daily average discrepancy is approximately $1.60 \mathrm{~W} / \mathrm{m}^{2} \mathrm{~K}$. The average difference in the DOE-2 model is approximately $20 \%$, and is the lowest. The highest is by SimpleCombined at 169\%, whilst the differences of TARP and MoWiTT are quite similar, at $28 \%$ and $30 \%$, respectively.

Figure 16 presents a comparison of the total cooling demand of the nine buildings between the embedded EnergyPlus algorithms and the coupled BES-CFD model. Table 3 gives the daily energy demand predicted by the different methods. All of the algorithms underestimations the demand when compared to the coupled model. The MoWiTT provides the closed predictions to the coupled method, but the smallest difference in the daily cooling demand is approximately $343 \mathrm{kWh}$. The largest difference is seen for the Adaptive model and is $958 \mathrm{kWh}$. Large differences can be observed from 7am to 10 am when the wind blows from $140^{\circ}, 10^{\circ}, 350^{\circ}$ and $230^{\circ}$. During this period, the coupled results are up to twice those estimated by the Adaptive model where a clear deviation between the coupled method and the other algorithms can be seen.

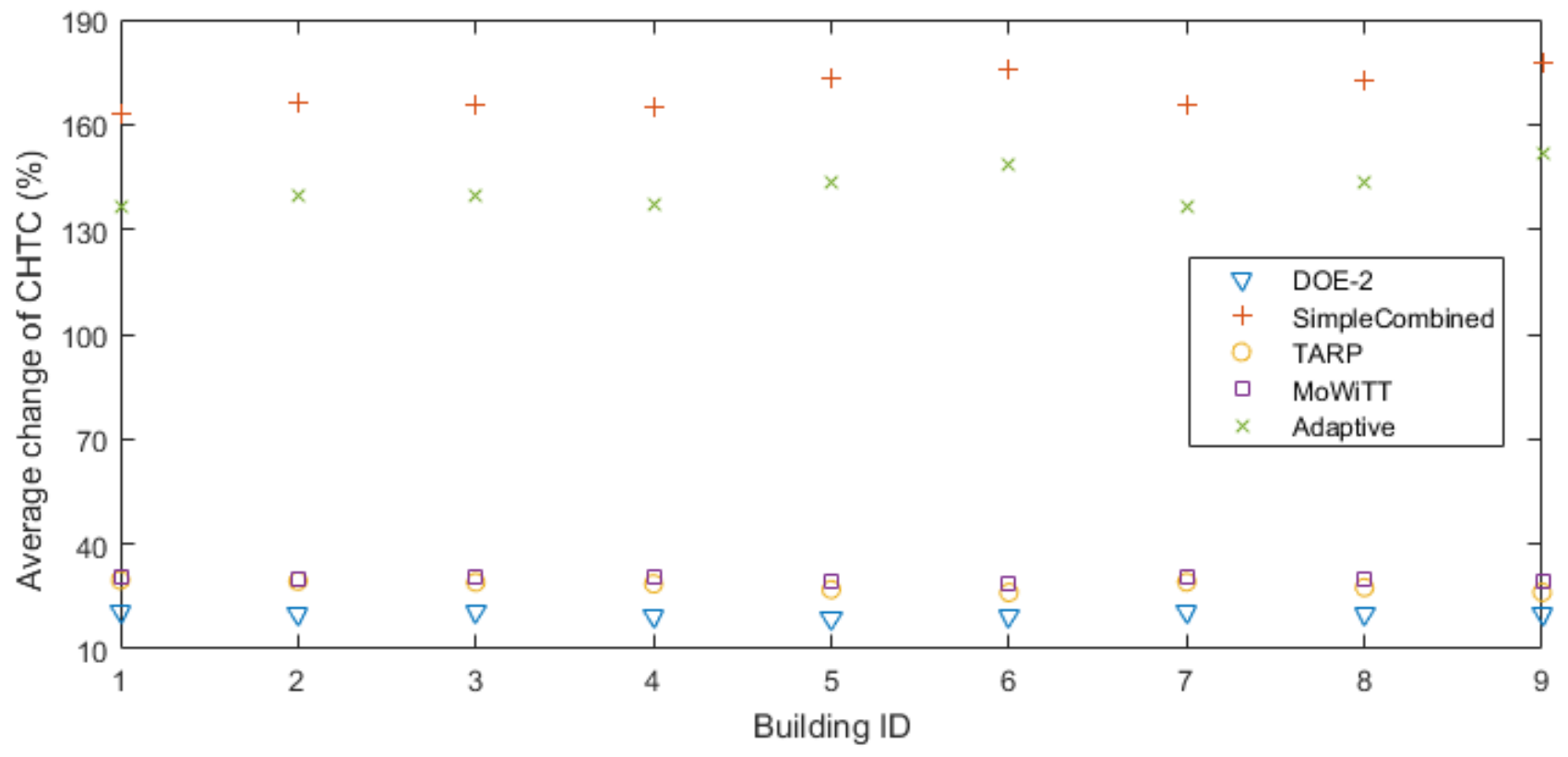

Figure 15 Change of CHTC by coupled method over the results by embedded algorithms 


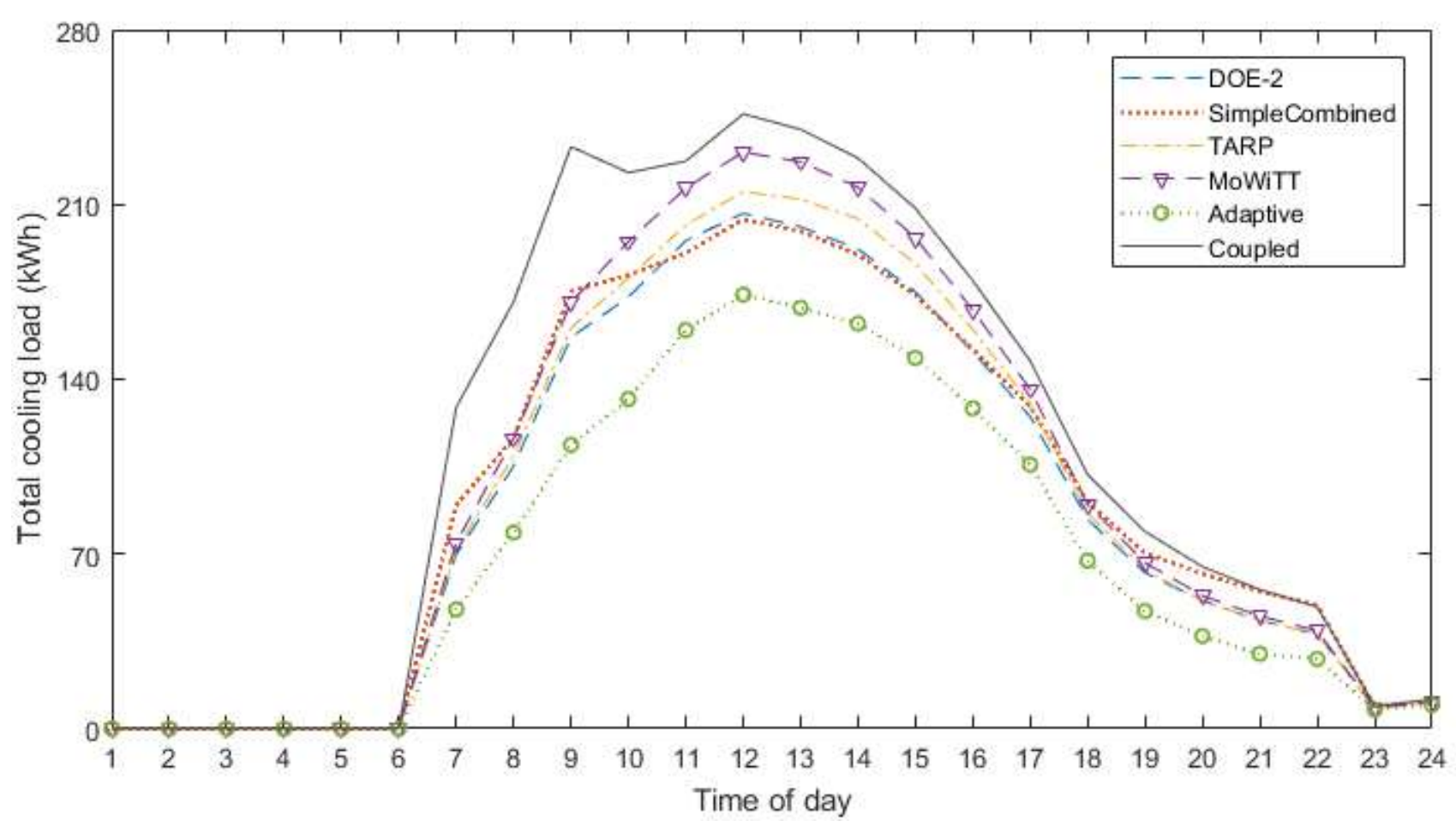

Figure 16 Total cooling load of nine commercial buildings throughout the test day by different methods

Table 3 Comparison of daily cooling demand by different methods

\begin{tabular}{lcccrrr}
\hline \hline \multirow{2}{*}{ Cooling demand $(\mathrm{kWh})$} & DOE-2 & SimpleCombined & TARP & MoWiTT & Adaptive & Coupled \\
\cline { 2 - 6 } & 2048.7 & 2149.3 & 2132.5 & 2261.4 & 1646.0 & 2603.9 \\
\hline \hline
\end{tabular}

\section{Conclusions}

The embedded CHTC algorithms used by many commercial building energy tools do not adequately consider the dynamic sheltering effects of neighbourhoods on buildings' exterior surfaces. Therefore, a framework that dynamically couples BES and CFD domains has been developed to enhance the prediction of heat convection prediction at buildings' exterior surfaces. The CFD domain of the framework has been validated using wind tunnel measurements of a sheltered block of nine buildings by the AIJ. Furthermore, a new BES model of a DoE benchmark case has also been developed. ENERGYPLUS and FLUENT have been employed as the BES and CFD tools, respectively. The main conclusions of this study are:

> The coupling process aims to achieve a good enough agreement between the BES and CFD domains on convective heat flux values. In this study, the surface temperature $\left(T_{s}\right)$ predicted by the BES tool and the CHTC $\left(q_{c}^{\prime \prime}\right)$ predicted by the CFD tool are the data shared between the two domains.

D ENERGYPLUS uses a simplified local climate and so it does not capture the vertical air temperature distribution as accurately as the CFD domain. To achieve coherence results, ENERGYPLUS requires a more realistic convection coefficient, which CFD domain has the potential to modify it.

$>$ Convergence between the BES and CFD domains for a single time-step is identified by a residual criterion of $T_{s}$ by the BES tool and $h_{c}$ by the CFD tool. Initially, the residuals of $T_{s}$ and $h_{c}$ were set 
to be $<1 \times 10^{-3}$, but was increased to $1 \times 10^{-2}$ to reduce the computational cost for some time-steps when convergence was not achieved within 20 iterations.

$>$ Fully dynamic coupling is realised by achieving convergence at each time-step of a simulation period. An analysis of an example hour during a test day shows that this coupling method can change the prediction of a building community's outdoor $q_{c}^{\prime \prime}$ by approximately $74 \%$. The prediction of hourly exterior convection energy is changed by over 64\% (including fenestration surfaces). Near-field buildings are shown to have a significant sheltering effect on others within the community. During the example hour, the standard deviation of $q_{c}^{\prime \prime}$ for all nine buildings increased by more than four times when compared to those predicted by the DOE-2 algorithm included in ENERGYPLUS.

> The change in CHTC by the fully dynamic coupling model is found to be significant when compared to the algorithms used by ENERGYPLUS. The SimpleCombined and DOE-2 models are found to be the worst and the best algorithms, respectively, to capture the dynamic CHTC. Even with the best matching DOE-2 model, there is a $20 \%$ difference in the daily average amendment of the $\mathrm{CHTC}$.

All ENERGYPLUS embedded algorithms are found to underestimate the cooling load of the case study buildings. The largest gap in the daily energy demand is estimated to be 957kWh predicted by the Adaptive model.

The proposed dynamic coupling method shows some significant advantages, but the investigation of the case study buildings is only for a specific condition, and so further investigation of general cases (stochastic morphology and meteorological conditions) is required. Future work will focus on statistically evaluating random hourly samples. It will seek to combine an enhanced CFD model of indoor natural ventilation with BES using a dynamic coupling technique to explore the potential advances in building energy demand assessment.

\section{Acknowledgement}

The authors would like to acknowledge the financial support from the Faculty of Engineering of The University of Nottingham, UK. 


\section{References}

1. Energy Information Administration and Government Pringting Office U.S., International Energy Outlook. 2017, U.S. Government Printing Office.

2. Balaras, C.A., et al., European residential buildings and empirical assessment of the Hellenic building stock, energy consumption, emissions and potential energy savings. Building and Environment, 2007. 42(3): p. 1298-1314.

3. National Statistics, Energy consumption in the UK, E.I.S. Department for Business, UK, Editor. 2016.

4. Cohen, J.E., Human Population: The Next Half Century. Science, 2003. 302(5648): p. 1172-1175.

5. Negrão, C.O.R., Integration of computational fluid dynamics with building thermal and mass flow simulation. Energy and Buildings, 1998. 27(2): p. 155-165.

6. Palyvos, J.A., A survey of wind convection coefficient correlations for building envelope energy systems' modeling. Applied Thermal Engineering, 2008. 28(8-9): p. 801-808.

7. Davies, M.G., Building heat transfer. 2004: John Wiley \& Sons.

8. Vollaro, A.d.L., G. Galli, and A. Vallati, CFD analysis of convective heat transfer coefficient on external surfaces of buildings. Sustainability, 2015. 7(7): p. 9088-9099.

9. Emmel, M.G., M.O. Abadie, and N. Mendes, New external convective heat transfer coefficient correlations for isolated low-rise buildings. Energy and Buildings, 2007. 39(3): p. 335-342.

10. Crawley, D.B., et al., Contrasting the capabilities of building energy performance simulation programs. Building and Environment, 2008. 43(4): p. 661-673.

11. Gilani, S., H. Montazeri, and B. Blocken, CFD simulation of stratified indoor environment in displacement ventilation: Validation and sensitivity analysis. Building and Environment, 2016. 95(Supplement C): p. 299-313.

12. Shirzadi, M., P.A. Mirzaei, and M. Naghashzadegan, Development of an adaptive discharge coefficient to improve the accuracy of cross-ventilation airflow calculation in building energy simulation tools. Building and Environment, 2018. 127(Supplement C): p. 277-290.

13. Allegrini, J., V. Dorer, and J. Carmeliet, Coupled CFD, radiation and building energy model for studying heat fluxes in an urban environment with generic building configurations. Sustainable Cities and Society, 2015. 19: p. 385-394.

14. Wang, X. and Y. Li, Predicting urban heat island circulation using CFD. Building and Environment, 2016. 99: p. 82-97.

15. Shirzadi, M., et al., Modelling enhancement of cross-ventilation in sheltered buildings using stochastic optimization. International Journal of Heat and Mass Transfer, 2018. 118(Supplement C): p. 758-772.

16. Mirzaei, P.A. and F. Haghighat, Pollution removal effectiveness of the pedestrian ventilation system. Journal of Wind Engineering and Industrial Aerodynamics, 2011. 99(1): p. 46-58.

17. Mirzaei, P.A. and F. Haghighat, A novel approach to enhance outdoor air quality: Pedestrian ventilation system. Building and Environment, 2010. 45(7): p. 1582-1593.

18. Shirzadi, M., M. Naghashzadegan, and P. A. Mirzaei, Improving the CFD modelling of cross-ventilation in highly-packed urban areas. Sustainable Cities and Society, 2018. 37: p. 451-465.

19. Negrao, C.O., Conflation of computational fluid dynamics and building thermal simulation. 1995, University of Strathclyde Glasgow. 
20. Srebric, J., Q. Chen, and P.D.L.R. Glicksman, A Coupled Airflow-and-Energy Simulation Program for Indoor Thermal Environment Studies (RP-927).

21. Djunaedy, E., J.L. Hensen, and M. Loomans, Toward external coupling of building energy and airflow modeling programs. ASHRAE Transactions, 2003. 109(2): p. 771-787.

22. Zhai, Z.J. and Q.Y. Chen, Performance of coupled building energy and CFD simulations. Energy and Buildings, 2005. 37(4): p. 333-344.

23. Beausoleil-Morrison, I., The adaptive conflation of computational fluid dynamics with whole-building thermal simulation. Energy and Buildings, 2002. 34(9): p. 857-871.

24. Zhai, Z. and Q.Y. Chen, Solution characters of iterative coupling between energy simulation and CFD programs. Energy and buildings, 2003. 35(5): p. 493-505.

25. Mochida, A., et al., Total analysis of cooling effects of cross-ventilation affected by microclimate around a building. Solar Energy, 2006. 80(4): p. 371-382.

26. Yi, Y.K. and N. Feng, Dynamic integration between building energy simulation (BES) and computational fluid dynamics (CFD) simulation for building exterior surface. Building Simulation, 2013. 6(3): p. 297308.

27. Allegrini, J., V. Dorer, and J. Carmeliet, Influence of morphologies on the microclimate in urban neighbourhoods. Journal of Wind Engineering and Industrial Aerodynamics, 2015. 144: p. 108-117.

28. Malys, L., M. Musy, and C. Inard, Microclimate and building energy consumption: study of different coupling methods. Advances in Building Energy Research, 2015. 9(2): p. 151-174.

29. Nikkho, S.K., et al., Quantifying the impact of urban wind sheltering on the building energy consumption. Applied Thermal Engineering, 2017. 116(Supplement C): p. 850-865.

30. Department of Energy U.S., EnergyPlus Engineering Reference. 2016.

31. Launder, B.E. and D.B. Spalding, Lectures in mathematical models of turbulence. 1972.

32. Architectural Institute of Japan, Guidebook for practical applications of CFD to pedestrian wind environment around buildings. Architectural Institute of Jpan.

33. Mirzaei, P.A. and J. Carmeliet, Dynamical computational fluid dynamics modeling of the stochastic wind for application of urban studies. Building and Environment, 2013. 70: p. 161-170.

34. Franke, J., Best practice guideline for the CFD simulation of flows in the urban environment. 2007: Meteorological Inst.

35. Zhang, R., P.A. Mirzaei, and J. Carmeliet, Prediction of the surface temperature of building-integrated photovoltaics: Development of a high accuracy correlation using computational fluid dynamics. Solar Energy, 2017. 147: p. 151-163.

36. Gousseau, P., B. Blocken, and G.J.F. van Heijst, Quality assessment of Large-Eddy Simulation of wind flow around a high-rise building: Validation and solution verification. Computers \& Fluids, 2013. 79(Supplement C): p. 120-133.

37. Schatzmann, M., H.R. Olesen, and J. Franke, COST 732 model evaluation case studies: approach and results. 2010: COST Office.

38. Tominaga, Y., Flow around a high-rise building using steady and unsteady RANS CFD: Effect of largescale fluctuations on the velocity statistics. Journal of Wind Engineering and Industrial Aerodynamics, 2015. 142(Supplement C): p. 93-103.

39. Chang, J.C. and S.R. Hanna, Air quality model performance evaluation. Meteorology and Atmospheric Physics, 2004. 87(1): p. 167-196. 
40. Tominaga, Y., et al., Cross comparisons of CFD prediction for wind environment at pedestrian level around buildings. Part, 2005. 2: p. 2661-2670.

41. Tominaga, Y., et al., AlJ guidelines for practical applications of CFD to pedestrian wind environment around buildings. Journal of Wind Engineering and Industrial Aerodynamics, 2008. 96(10): p. 17491761.

42. ANSYS, Guide, ANSYS FLUENT User. Inc., USA, November, 2011.

43. Deru, M., et al., US Department of Energy commercial reference building models of the national building stock. 2011.

44. Department of Energy U.S. Commercial Reference Buildings. 2011 [cited 2017 01.09]; Available from: https://energy.gov/eere/buildings/commercial-reference-buildings.

45. Department of Energy U.S., Building Technologies Office U.S., and National Renewable Energy Laboratory, Weather Data. 